Purdue University

Purdue e-Pubs

CTRC Research Publications

Cooling Technologies Research Center

2019

\title{
Design of an area-scalable two-layer evaporator wick for high-heat-flux vapor chambers
}

S. Sudhakar

Purdue University

J.A. Weibel

Purdue University, jaweibel@purdue.edu

S V. Garimella

Purdue University, sureshg@purdue.edu

Follow this and additional works at: https://docs.lib.purdue.edu/coolingpubs

Sudhakar, S.; Weibel, J. A.; and Garimella, S V., "Design of an area-scalable two-layer evaporator wick for high-heat-flux vapor chambers" (2019). CTRC Research Publications. Paper 348.

http://dx.doi.org/10.1109/TCPMT.2018.2860961

This document has been made available through Purdue e-Pubs, a service of the Purdue University Libraries. Please contact epubs@purdue.edu for additional information. 


\title{
Design of an Area-Scalable Two-Layer Evaporator Wick for High-Heat-Flux Vapor Chambers
}

\author{
Srivathsan Sudhakar, Justin A. Weibel ${ }^{1}$, and Suresh V. Garimella
}

\begin{abstract}
A hybrid two-layer evaporator wick is proposed for passive, high-heat-flux dissipation over large areas using a vapor chamber heat spreader. For such applications, the evaporator wick layer must be designed to simultaneously minimize the device temperature rise and minimize the flow resistance to capillary feeding of the wick. This requires a strategy that exploits the benefits of a thin wick for reduced thermal resistance and a thick wick for liquid feeding. In the present design, a thick cap layer of wick material evenly routes liquid to a thin, low-thermal-resistance base layer through an array of vertical liquid-feeding posts. This twolayer structure decouples the functions of liquid resupply (cap layer) and capillary-fed boiling heat transfer (base layer), making the design scalable to heat input areas of $\sim 1$ $\mathrm{cm}^{2}$ for operation at $1 \mathrm{~kW} / \mathrm{cm}^{2}$. A reduced-order model is developed to demonstrate the potential performance of a vapor chamber incorporating such a two-layer evaporator wick design. The model comprises simplified hydraulic and thermal resistance networks for predicting the capillarylimited maximum heat flux and the overall thermal resistance, respectively. The reduced-order model is validated against a higher fidelity numerical model and then used to analyze the performance of the vapor chamber with varying two-layer wick geometric feature sizes. The two-layer wick design is found to sustain liquid feeding at higher heat fluxes, without reaching the capillary limit, compared to single-layer evaporator wick designs.
\end{abstract}

Index Terms - Capillary-fed boiling, Dryout, Evaporator wick, Two-layer wick, High-heat-flux dissipation, Thermal resistance, Vapor chamber.

\section{NOMENCLATURE}

$\begin{array}{ll}A & \text { area }\left(\mathrm{m}^{2}\right) \\ c_{1-9} & \text { constants } \\ C & \text { empirical constant (in equation }(21)) \\ d & \text { diameter }(\mathrm{m}) \\ d_{\text {part }} & \text { mean particle diameter }(\mathrm{m}) \\ d_{\text {pore }} & \text { mean pore diameter }(\mathrm{m}) \\ f & \text { friction factor } \\ h_{f g} & \text { heat of vaporization }(\mathrm{J} / \mathrm{kgK})\end{array}$

This material is based upon work supported by Toyota Motor Engineering and Manufacturing North America, Inc. under an Advanced Research Collaboration with Dr. Feng Zhou and Dr. Ercan M. Dede at the Toyota Research Institute of North America

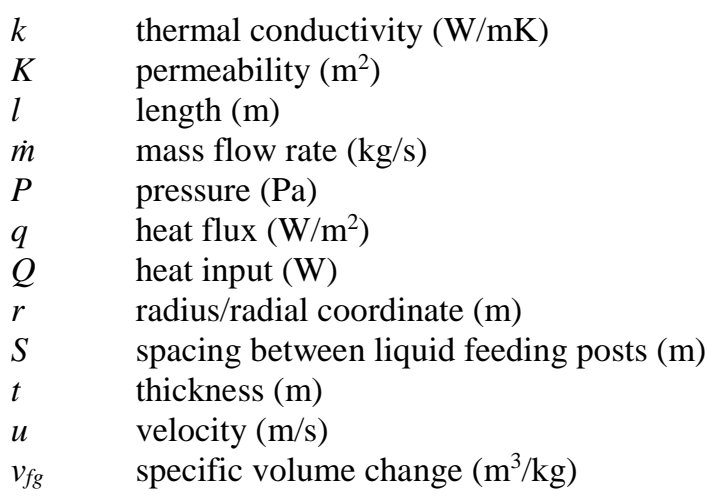

\section{A. Greek symbols \\ $\mu \quad$ dynamic viscosity $(\mathrm{kg} / \mathrm{ms})$ \\ $v \quad$ kinematic viscosity $\left(\mathrm{m}^{2} / \mathrm{s}\right)$ \\ $\rho$ density $\left(\mathrm{kg} / \mathrm{m}^{3}\right)$ \\ $\sigma \quad$ surface tension $(\mathrm{N} / \mathrm{m})$ \\ $\phi \quad$ porosity}

\section{B. Subscripts}

base base wick

boil capillary-fed boiling

bulk bulk wick

c capillary

cap cap layer

cond condenser

condn conduction

core vapor core

$\mathrm{Cu}$ copper

eff effective

evap evaporator

grid grid-patterned wick

$h \quad$ homogeneous wick

$l \quad$ liquid

post liquid-feeding post

sat saturation

space space between liquid-feeding posts

$v \quad$ vapor

vent vapor vent

wall vapor chamber walls

S. Sudhakar, J.A. Weibel and S.V. Garimella are with the School of Mechanical Engineering and Birck Nanotechnology Center, Purdue University, West Lafayette, IN 47907 USA (e-mail: ssudhak@purdue.edu; jaweibel@purdue.edu; sureshg@purdue.edu)

${ }^{1}$ Corresponding author 


\section{INTRODUCTION}

$\mathrm{V}$ apor chambers offer an effective means of spreading heat from a localized source to a larger surface area while incurring a small temperature gradient. The heat input to the evaporator of a vapor chamber is absorbed by a change in phase of a working fluid. Vapor thus formed flows to the condenser section, where heat is rejected and the fluid condenses back to the liquid phase. A porous wick structure lining the inside of the vapor chamber is responsible for passively transporting condensed liquid back to the heat input area by capillary forces. By operating in this two-phase cycle, passive heat spreading may be accomplished at a temperature gradient that can be significantly lesser than in the case of conduction-based solid spreader layers.

The amount of heat input to the vapor chamber dictates the phase-change behavior in the evaporator wick [1]. At low input heat fluxes, the wick operates in a regime wherein evaporation occurs from the liquid menisci sustained at the top of the saturated wick. As heat flux is increased, the menisci recede into the bulk of the wick with increased curvature, providing more capillary pressure for resupply, compensating for the increased liquid flow rate due to evaporation. Depending on the size of the heat input area and the vapor chamber design, further increases in heat flux may cause the menisci to completely recede and dry out (reaching the so-called capillary limit); alternatively, if the surface superheat becomes sufficiently large prior to capillary dryout, vapor bubble nucleation can occur in the wick structure leading to a capillary-fed boiling regime. In some wick structures, incipience of vapor bubbles can completely cut off the capillary resupply pathway, causing immediate dryout via the so-called boiling limit. Early studies that reported sustained capillary-fed boiling from porous wick structures [2,3] observed a sharp decrease in the thermal resistance when boiling was initiated. However, sustained boiling in the mesh wick structures [4] reduced the crosssectional area available for liquid flow, thereby incurring a large pressure drop responsible for premature dryout, at heat fluxes below the notional capillary limit, despite the potential for a reduction in the thermal resistance.

Sintered metal wicks provide relatively higher capillary pressure and effective thermal conductivities in comparison to other conventional wick structures [1]. In addition, the highly tortuous nature of the stochastic network of pores in sintered metal wicks can sustain liquid supply during capillary-fed boiling conditions, making them suitable for high-heat-flux vapor chamber applications in which nucleation is likely to occur. Several studies have evaluated homogeneous sintered metal wicks for dissipating high heat fluxes when operated in the capillary-fed boiling regime [5-8] and identified the critical wick geometric parameters that governed thermal performance and dryout under these conditions. Parametric investigations of wick thickness reported that higher thicknesses yielded higher dryout heat fluxes for homogeneous sintered metal screen wicks [6] and biporous sintered powder wicks [7]. While thicker wicks were capable of providing a larger cross-sectional area for liquid resupply to prevent dryout, thick sintered wicks can result in a large surface superheat during capillary-fed boiling operation [7]. Thin homogeneous sintered metal powder wicks on the order of $\sim 200 \mu \mathrm{m}$ in thickness can provide a low thermal resistance to boiling [8], but cannot sustain liquid supply at high heat fluxes.

In comparison to homogeneous wicks, for which there is an intrinsic tradeoff between the maximum supported heat flux and thermal conductance as wick thickness is varied, various studies in the literature have developed nonhomogeneous wick morphologies to circumvent these limitations. Such heterogeneous wicks may include patterned features to ease vapor removal and provide dedicated liquid-feeding pathways to prevent dryout during capillary-fed boiling operation. Mughal and Plumb [3] concluded that providing a highpermeability pathway for vapor flow, by cutting channels in the evaporator wick, doubled the dryout heat flux. Ju et al. [9] developed wick structures that used lateral or columnar wick arteries to supply liquid to a thin wicking layer; these wicks were able to dissipate $\sim 350 \mathrm{~W} / \mathrm{cm}^{2}$ input over a $1 \mathrm{~cm}^{2}$ evaporator area. Weibel et al. [10] evaluated grid-patterned sintered wicks that provided vapor removal pathways during boiling, reducing the evaporator surface superheat by $30 \%$ compared to uniform sintered wick layers. Zhao and Chen [11] tested a micro-grooved sintered powder wick that improved the dryout heat flux over a uniform wick by $300 \%$. These studies have demonstrated that providing separate liquid flow and vapor extraction pathways can improve the performance of an evaporator wick operating at high heat fluxes.

Next-generation high performance electronic systems call for the removal of extreme heat fluxes of about $1 \mathrm{~kW} / \mathrm{cm}^{2}$ [12], while maintaining the surface temperature within specified limits to ensure device reliability. While heat fluxes of $\sim 1$ $\mathrm{kW} / \mathrm{cm}^{2}$ have been dissipated by passively-fed wick structures, these demonstrations have been limited by incurring excessive surface temperatures (e.g., $147 \mathrm{~K}$ superheat [7]) or being restricted to very small hotspot sizes of $0.04 \mathrm{~cm}^{2}[13,14]$ or less [15]. Several studies have pointed to a very strong dependence of the maximum heat flux supported by capillary-fed boiling wick structures to the heat input area $[14,16]$. For example, Cai and Chen [14] showed that carbon nanotube biwick structures were capable of removing significantly higher heat fluxes of $938 \mathrm{~W} / \mathrm{cm}^{2}$ from smaller heaters $\left(0.04 \mathrm{~cm}^{2}\right)$ as compared to dryout occurring at as low as $195 \mathrm{~W} / \mathrm{cm}^{2}$ for a larger heated area of $1 \mathrm{~cm}^{2}$. Weibel and Garimella [17] have comprehensively reviewed the recent progress and current limitations in design and fabrication of evaporator wick structures for high heat flux applications.

This study evaluates an evaporator wick design that combines different important functionalities revealed in the literature to potentially realize $\sim 1 \mathrm{~kW} / \mathrm{cm}^{2}$ heat dissipation over heat input areas as large as $1 \mathrm{~cm}^{2}$ and at thermal resistances suitable for electronics cooling applications. The two-layer design comprises a thin porous wick layer in which the liquid charge undergoes boiling, fed with a continuous supply of liquid by an array of porous vertical posts capped by a thick wick layer. The thin wick layer imposes a low thermal resistance during capillary-fed boiling, while the thick cap layer provides a high-permeability route for liquid feeding from above through the posts. The two-layer wick structure concept is first presented, and then a reduced-order model is developed to predict the performance of a vapor chamber incorporating this structure in the evaporator. The reduced-order model is 


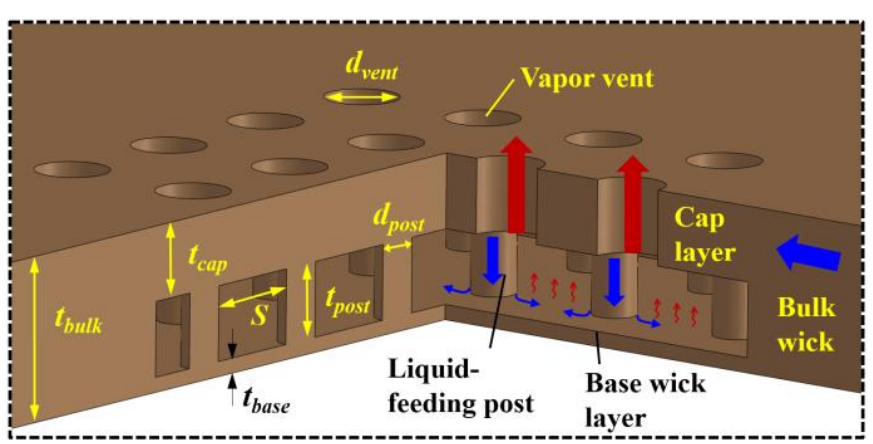

(a)

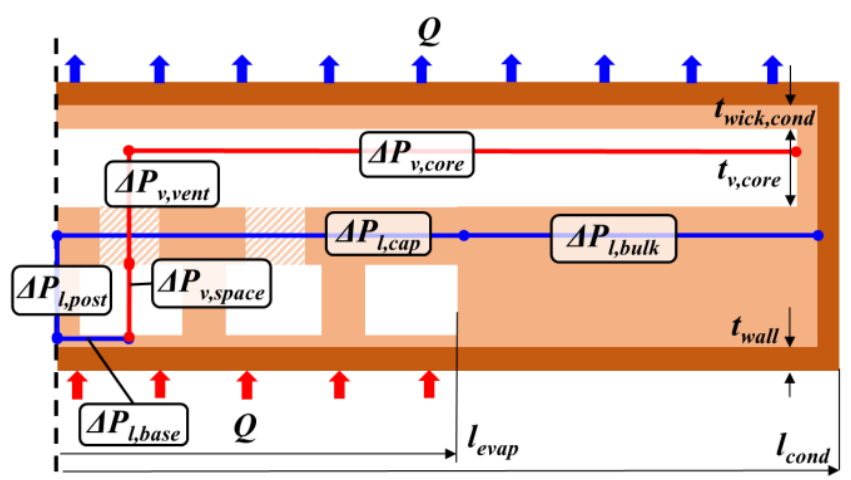

(b)

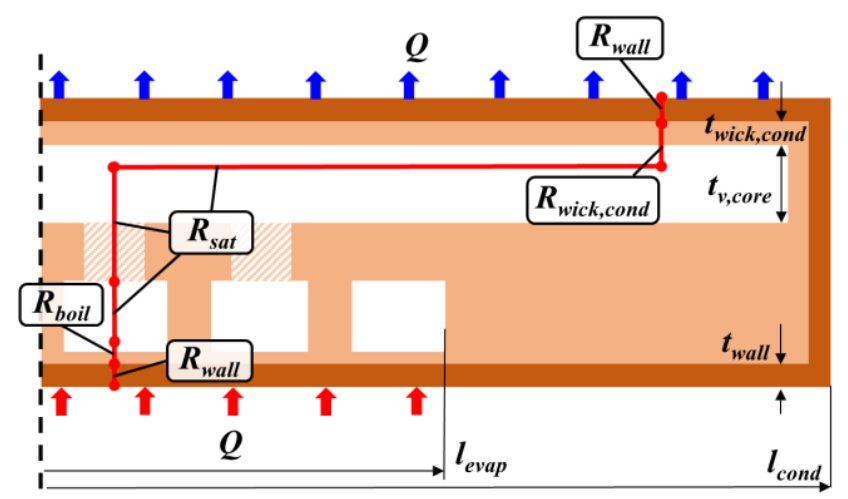

(c)

Fig. 1 (a) A three-dimensional schematic drawing of the proposed two-layer evaporator wick structure is shown with liquid (blue) and vapor (red) flow pathways indicated. The view is cut by planes intersecting the liquid-feeding posts (left) and the vapor vents (right) to reveal the internal structure. Cross-sectional schematic diagrams are shown with the twolayer evaporator wick structure incorporated within a vapor chamber heat spreader (with one half of the geometry shown); (b) the liquid-phase $\left(\Delta P_{l}\right)$ and vapor-phase $\left(\Delta P_{v}\right)$ pressure drops and (c) thermal resistances $(R)$ are drawn along the primary fluid flow path (not to scale).

validated against a higher-fidelity numerical model and then used to obtain parametric trends in the wick pressure drop and evaporator thermal resistance. The two-layer wick performance is benchmarked against conventional single-layer wick concepts.

\section{TWO LAYER EVAPORATOR WICK CONCEPT}

Fig. 1 shows a three-dimensional drawing of the proposed two-layer wick structure, as well as a cross-sectional schematic diagram of this two-layer structure incorporated as the evaporator inside a vapor chamber heat spreader. The condensed working fluid returns to the evaporator section from the periphery of the vapor chamber through a conventional bulk wick (thickness $t_{b u l k}$ ). Liquid is routed from the bulk wick surrounding the evaporator section into a relatively thick wick cap layer (thickness $t_{c a p}$ ) into an array of vertical liquid-feeding posts (diameter $d_{\text {post }}$ ). These posts uniformly distribute the liquid to a thin base wick (thickness $t_{\text {base }}$ ). Vapor generated by capillary-fed boiling in the base wick escapes through gaps between the posts (spacing $S$ ) and on through vapor vents in the cap wick layer (diameter $d_{v e n t}$ ) into the vapor core.

Although thinner wicks provide lower thermal resistance during capillary-fed boiling compared to thicker wicks, they cannot sustain liquid resupply at high heat fluxes. In order to leverage the low thermal resistance offered by a thin evaporator wick, the two-layer structure uses the thick layer as a means to adequately feed liquid from the top. Alternative strategies have explored lateral feeding using wedge-shaped wick geometries [18] and converging arteries [19] that supply liquid within a central evaporator. However, the liquid-feeding structures in these approaches occupy a part of the base area, inherently reducing the available evaporator area for the phase change process. The proposed top-down feeding approach decouples the liquid-feeding structure (i.e., the wick cap layer) from the capillary-fed boiling region in the evaporator; the complete evaporator footprint area is made available to the wick cap layer for capillary supply. Prior top-down feeding approaches [20] consisted of vertical posts covered by a uniform porous wick, directly connected from the condenser side to the evaporator. These long arteries spanning the entire thickness of a vapor chamber incur an increased pressure drop that negates any improvement over lateral feeding [9]. Regardless of the vapor chamber design, the two-layer evaporator structure allows for different designs of the thickness and length of the liquidfeeding posts.

Under steady operation of a vapor chamber, the vapor core is at saturated condition, and the local vapor pressure and temperature are related via the saturation curve. There can be a large pressure gradient in the vapor exiting a wick through tortuous pathways during capillary-fed boiling, resulting in a high evaporator temperature. High-permeability vapor venting with grooved-wick [11] and patterned-wick [10] structures has been shown to decrease the surface superheat significantly and extend the dryout heat flux. The vapor vents in the proposed two-layer evaporator wick structure provide a relatively unimpeded pathway for vapor to exit through the cap wick layer via the gaps between the liquid-feeding posts.

\section{REDUCED-ORDER MODEL OF TWO-LAYER WICK}

A reduced-order model is developed to estimate the internal pressure drops and thermal resistances in a vapor chamber incorporating the two-layer evaporator wick design. This model is used to find the overall thermal resistance of the vapor chamber and to predict if the capillary pressure of the porous 
wick structure is sufficient to maintain operation at a given heat flux for various two-layer wick designs.

A schematic diagram showing the predominant pressure drops and thermal resistances considered in the model is shown in Fig. 1 (b) and (c), respectively. The diagrams show one half of the geometry of a square vapor chamber, with evaporator and condenser square edge lengths $l_{\text {evap }}$ and $l_{\text {cond }}$, respectively. A constant heat input $Q$ at the evaporator is rejected from the condenser side of the vapor chamber. There is a viscous liquidphase pressure drop in the bulk wick structure from the periphery to the evaporator $\left(\Delta P_{l, b u l k}\right)$, along the cap wick layer $\left(\Delta P_{l, \text { cap }}\right)$, through the liquid-feeding posts $\left(\Delta P_{l, p o s t}\right)$, and to the furthest extent in the thin base wick layer $\left(\Delta P_{l, \text { base }}\right)$. Vapor flow incurs a pressure drop as it passes through the space between the posts $\left(\Delta P_{v, \text { space }}\right)$, across the vapor vents $\left(\Delta P_{v, v e n t}\right)$, and outward in the vapor core $\left(\Delta P_{v, \text { core }}\right)$. The pressure drop for the wick along the side wall of the vapor chamber is assumed to be negligible compared to the bulk liquid pressure due to the small thickness of the vapor chamber relative to the lateral dimensions. The evaporator temperature rise above saturation is governed by conduction resistances across the evaporator and condenser walls $\left(R_{\text {wall }}\right)$ and condenser-side wick $\left(R_{\text {wick, cond }}\right)$, the capillary-fed boiling resistance in the base wick $\left(R_{b o i l}\right)$, and the thermal resistance associated with the total differential in the saturation pressure of the vapor $\left(R_{s a t}\right)$. Note that the conduction resistance through the wick on the evaporator side is effectively bypassed during boiling because nucleation occurs from the substrate-wick interface. Moreover, the condensation resistance across the liquid-vapor interface (on the condenser side) is assumed to be negligible compared to the conduction resistances [21].

The model assumes that the porous wick is composed of sintered particles of mean diameter $d_{\text {part }}$; the effective pore radius is taken as $r_{\text {pore }}=0.21 d_{\text {part }}$ [1]. The capillary pressure of the wick is calculated directly from the pore radius, assuming a highly wetting fluid, as

$$
P_{c}=\frac{2 \sigma}{r_{\text {pore }}}
$$

For a wick porosity of $\phi$, the liquid permeability is calculated as [1]

$$
K=\frac{d_{\text {part }}^{2} \phi^{3}}{150(1-\phi)^{2}}
$$

To simplify the problem, the rectangular vapor chamber is modeled as a cylindrical disk, with effective evaporator $\left(r_{\text {evap }}\right)$ and condenser $\left(r_{\text {cond }}\right)$ radii calculated such that the footprint area is equivalent to the square edge lengths $l_{\text {evap }}$ and $l_{\text {cond }}$.

\section{A. Fluid pressure drops}

The liquid-phase pressure drops are calculated using the onedimensional governing momentum equation for radial flow in porous media given by

$$
\frac{1}{\phi^{2}}\left(u_{l} \frac{\partial u_{l}}{\partial r}\right)=-\frac{1}{\rho_{l}} \frac{\partial P}{\partial r}-\frac{v_{l} u_{l}}{K}+\frac{v_{l}}{\phi}\left[\frac{1}{r} \frac{\partial}{\partial r}\left(r \frac{\partial u_{l}}{\partial r}\right)-\frac{u_{l}}{r^{2}}\right]
$$

where $u_{l}$ is the liquid flow velocity in the radial direction. A total mass flow rate is calculated from the heat input,

$$
\dot{m}_{\text {total }}=Q / h_{f g}
$$

To calculate the bulk liquid pressure drop $\left(\Delta P_{l, \text { bulk }}\right)$, a bulk velocity is calculated from the total mass flow rate as

$$
u_{l, b u l k}(r)=\dot{m}_{\text {total }} /\left(\rho_{l} 2 \pi r t_{\text {bulk }}\right)
$$

Integrating equation (3) from the condenser radius to the evaporator radius gives the value of the pressure drop as

$$
\begin{aligned}
& \Delta P_{l, \text { bulk }}=\frac{-\rho_{l} c_{1}^{2}}{2 \phi^{2}}\left(\frac{1}{r_{\text {evap }}^{2}}-\frac{1}{r_{\text {cond }}^{2}}\right)+\frac{\mu_{l} c_{1}}{K} \ln \left(\frac{r_{\text {cond }}}{r_{\text {evap }}}\right) ; \\
& c_{1}=\frac{\dot{m}_{\text {total }}}{2 \pi \rho_{l} t_{\text {bulk }}}
\end{aligned}
$$

(a)

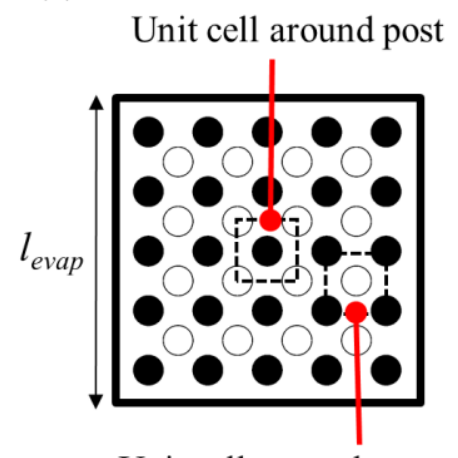

Unit cell around vent (b)

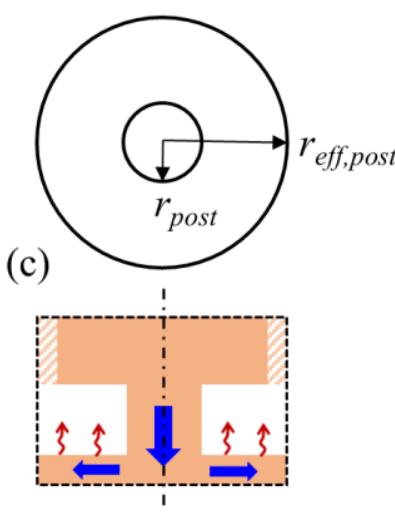

(d)

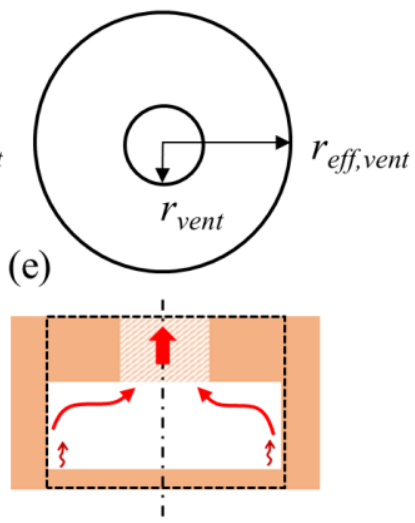

Fig. 2 (a) Plan-view diagram of the evaporator footprint area of side length $l_{\text {evap }}$, for an example $5 \times 5$ square array of liquidfeeding posts (filled circles) and an offset $4 \times 4$ square array of vapor vents (open dots). Square unit cells around one post and one vent are outlined. The square unit cells are approximated by axisymmetric radial unit cells with (b,d) plan and (c,e) side views shown. 
Liquid pressure drop along the cap layer is calculated assuming a uniform extraction of liquid from the cap underside area to the posts below. The mass flow rate of liquid in the cap layer is thereby a function of radial position and decreases from $\dot{m}_{\text {total }}$ at the evaporator periphery $\left(r_{\text {evap }}\right)$ to zero at the center:

$$
\dot{m}_{l, \text { cap }}(r)=\dot{m}_{\text {total }}\left(r^{2} / r_{\text {evap }}^{2}\right)
$$

A cap-layer liquid flow velocity is calculated as

$$
u_{l, c a p}(r)=\dot{m}_{l, c a p} /\left(\rho_{l} 2 \pi r t_{c a p, e f f}\right)
$$

where, to account for the reduced area available for flow due to the vapor vents, a reduced effective thickness of the cap layer

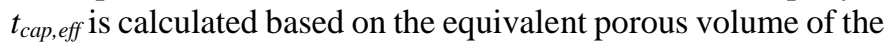
cap layer. Integrating equation (3) from $r=r_{\text {evap }}$ to $r=0$, the cap-layer pressure drop is,

$$
\Delta P_{l, c a p}=\rho_{l}\left[\frac{c_{2}{ }^{2}}{\phi^{2}}+\frac{v_{l} c_{2}}{K}\right] \frac{r_{\text {evap }}^{2}}{2} ; c_{2}=\frac{\dot{m}_{\text {total }}}{2 \pi \rho_{l} r_{\text {evap }}{ }^{2} t_{\text {cap }, \text { eff }}}
$$

Liquid pressure drop through each liquid-feeding post is calculated assuming uniform axial flow in a cylindrical porous medium:

$$
\Delta P_{l, p o s t}=\frac{v_{l} \dot{m}_{\text {post }}}{\pi r_{\text {post }}^{2} K} t_{\text {post }}
$$

where $t_{\text {post }}$ is the post height. The total mass flow rate is divided equally through all posts, i.e., $\dot{m}_{\text {post }}=\dot{m}_{\text {total }} / N_{\text {post }}$, where $N_{\text {post }}$ is the number of posts.

For calculation of the liquid pressure drop through the base wick layer $\left(\Delta P_{l, \text { base }}\right)$, a unit cell around each post in the evaporator footprint area is considered. Fig. 2 (a) shows a plan view of the two-layer wick evaporator footprint area; a square unit cell geometry around a post is outlined. This square unit cell is approximated as an axisymmetric radial geometry (Fig. $2(\mathrm{~b}-\mathrm{c}))$ centered at the post $\left(r_{\text {post }}\right)$ and extended outward to an effective radius $\left(r_{\text {eff;post }}\right)$. The value of this effective radius is calculated by equating the circular and square areas,

$$
\pi r_{\text {eff }, \text { post }}^{2}=\frac{l_{\text {evap }}^{2}}{N_{\text {post }}}
$$

The base layer liquid pressure drop is calculated considering radially outward flow from the center of each post to the effective radius $\left(r_{\text {eff,post }}\right)$ where the liquid evaporates completely. It is assumed that capillary-fed boiling only occurs in the footprint area not covered by the posts, i.e., the heat flux becomes

$$
q=\frac{Q}{\pi\left(r_{\text {evap }}^{2}-N_{\text {post }} r_{\text {post }}^{2}\right)}
$$

The mass flow rate of liquid flowing radially outward in the base wick increases from $r=0$ up to the post radius $\left(r=r_{\text {post }}\right)$ as liquid is fed from the post uniformly and decreases outside the post radius due to vaporization until complete evaporation at $r=r_{\text {eff,post: }}$

$$
\dot{m}_{l, \text { base }}(r)=\left\{\begin{array}{l}
\dot{m}_{\text {post }}\left[\frac{r^{2}}{r_{\text {post }}^{2}}\right] \quad 0 \leq r \leq r_{\text {post }} \\
\dot{m}_{\text {post }}\left[\frac{r_{\text {eff, post }}^{2}-r^{2}}{r_{\text {eff, post }}^{2}-r_{\text {post }}^{2}}\right] \quad r_{\text {post }} \leq r \leq r_{\text {eff }, \text { post }}
\end{array}\right.
$$

Equation (3) is integrated from $r=0$ to $r=r_{\text {eff,post }}$ with an associated liquid flow velocity, $u_{l, \text { base }}=\dot{m}_{l, \text { base }} /\left(2 \pi \rho_{l} r t_{\text {base }}\right)$, to give

$$
\begin{aligned}
\Delta P_{l, \text { base }}= & \left(\frac{\rho_{l} c_{3}^{2}}{\phi^{2}}+\frac{\mu_{l} c_{3}}{K}\right) \frac{r_{\text {post }}{ }^{2}}{2}+ \\
& \frac{\mu_{l} c_{4}}{K_{\text {eff }}}\left(\ln \left(\frac{r_{\text {eff }, \text { post }}}{r_{\text {post }}}\right)-\frac{r_{\text {eff }, \text { post }}^{2}-r_{\text {post }}^{2}}{2 r_{\text {eff }, \text { post }}^{2}}\right)+ \\
& \frac{\rho_{l} c_{4}^{2}}{\phi_{\text {eff }}^{2}}\left(\frac{1}{r_{\text {eff }, \text { post }}^{2}}-\frac{1}{2 r_{\text {post }}^{2}}-\frac{r_{\text {post }}^{2}}{2 r_{\text {eff }, \text { post }}^{4}}\right)
\end{aligned}
$$

where,

$$
c_{3}=\frac{\dot{m}_{\text {post }}}{2 \pi \rho_{l} t_{\text {base }} r_{\text {post }}^{2}} ; c_{4}=\frac{\dot{m}_{\text {post }}}{2 \pi \rho_{l} t_{\text {base }}\left(1-r_{\text {post }}^{2} / r_{\text {eff }, \text { post }}{ }^{2}\right)}
$$

In the above equation, values for the effective porosity $\phi_{\text {eff }}$ and effective permeability $K_{\text {eff }}$ are altered accounting for a reduced area available for liquid flow due to vapor formation in the wick. This change is confined to the region where boiling occurs, i.e., from $r=r_{\text {post }}$ to $r=r_{\text {eff,post }}$. To calculate the area reduction during boiling, the wick is assumed to be composed of spherical particles in a cubic packing. Following Ref. [22], pseudo-vapor columns are assumed to be sustained in pore spaces during capillary-fed boiling, and the porous structure is represented as a series of vapor columns in between an extended surface of copper particles. Based on the expressions for the dimensions of these vapor columns [22], the area reduction for liquid flow is found based on the geometry of the cubic-packed spheres. This area reduction is equated to a porosity reduction and a new value of porosity $\phi_{\text {eff }}$ is found. The reduced permeability $K_{\text {eff }}$ is found using equation (2) with this new porosity value.

Depending on the specific geometry chosen for the two-layer wick structure, vapor flow through the spaces between the posts is better represented using either one-dimensional upward flow (if the posts are relatively long and closely spaced) or radial flow (if the posts are relatively short and widely spaced). The current model calculates both one-dimensional approximations and the highest value is taken as a conservative estimate of this pressure drop $\left(\Delta P_{v, \text { space }}\right)$. For both cases, vapor is assumed to be formed directly above the base wick, where boiling occurs, in a region from $r=r_{\text {vent }}$ to $r=r_{\text {eff, vent }}$ within a unit cell around each vent, as shown in Fig. 2 (d-e). Because the number of vents is smaller than the number of liquid-feeding posts, the mass flow rate of vapor in a vent unit cell is calculated as $\dot{m}_{v}=\dot{m}_{\text {post }}$ $\left(N_{\text {pos }} / N_{\text {vent }}\right)$. For the upward flow case, the vapor flows upward in the cylindrical area of radius $r_{\text {eff, vent }}$; a Hagen-Poiseuille velocity profile and a corresponding pressure drop are calculated. For the radial flow case, vapor is assumed to flow 
radially inward from $r=r_{\text {eff,vent }}$ to $r=r_{\text {vent }}$, where it escapes into the vents above. (see the side view of the vapor vent unit cell in Fig. 2 (e)). In the radial flow case, the mass flow rate is a function of the radial position as vapor mass is being accumulated during the inward flow over the boiling area; the mass flow rate increases from a value of zero at $r=r_{\text {eff, vent }}$ to $\dot{m}_{v}$ at $r=r_{\text {vent }}$,

$$
\dot{m}_{v, \text { space }}(r)=\dot{m}_{v}\left[\frac{r_{\text {eff }, \text { vent }}^{2}-r^{2}}{r_{\text {eff }, \text { vent }}^{2}-r_{\text {vent }}^{2}}\right]
$$

The corresponding pressure drop is calculated by integrating the one-dimensional governing momentum equation for radial flow given by

$$
u_{v} \frac{\partial u_{v}}{\partial r}=-\frac{1}{\rho_{v}} \frac{\partial P}{\partial r}+v_{v}\left[\frac{\partial}{\partial r}\left(\frac{1}{r} \frac{\partial\left(r u_{v}\right)}{\partial r}\right)\right]
$$

where $u_{v}=\dot{m}_{v, \text { space }}(r) /\left(2 \pi \rho_{v} r t_{\text {post }}\right)$ is the vapor flow velocity in the radial direction, to obtain

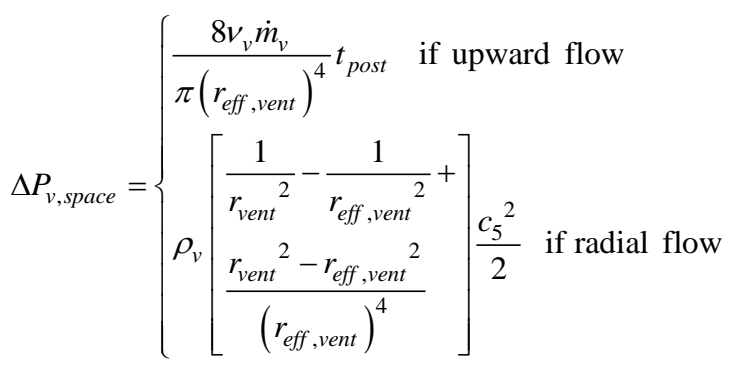

where,

$$
c_{5}=\frac{\dot{m}_{v}}{2 \pi \rho_{v} t_{\text {post }}\left(1-\frac{\left.{r_{\text {vent }}{ }^{2}}_{r_{\text {eff, vent }}{ }^{2}}\right)}{2}\right)}
$$

Minor losses are included to account for the sudden contraction into the vapor vents from the space below, based on an empirical correlation for abrupt contractions in cylindrical pipes [23],

$$
\Delta P_{v, \text { contraction }}=\left[1-\left(\frac{r_{\text {vent }}}{r_{\text {eff }, \text { vent }}}\right)^{4}+K_{m}\right] \frac{1}{2} \rho_{v} v_{\text {vent }}^{2}
$$

where

$$
K_{m}= \begin{cases}1.2+\frac{38}{\mathrm{Re}_{\text {vent }}} & \mathrm{Re}_{\text {vent }}<2000 \\ \frac{1}{2}\left(1-\frac{r_{\text {vent }}}{r_{\text {eff, vent }}}\right)^{2} & \mathrm{Re}_{\text {vent }}>2000\end{cases}
$$

where $K_{m}$ is the minor loss coefficient, which depends on the Reynolds number of flow through the vent, $\operatorname{Re}_{v e n t}=2 \rho_{v} v_{v e n t}$ $r_{v e n} / \mu_{v}$. Pressure drop through the cylindrical vapor vents is calculated using a Hagen-Poiseuille flow approximation, with a fully developed friction factor used based on the flow Reynolds number [23],

$$
\Delta P_{v, \text { vent }}=\left[\frac{f t_{\text {cap }}}{2 r_{\text {vent }}}\right] \frac{1}{2} \rho_{v} v_{\text {vent }}^{2}
$$

where

$$
f= \begin{cases}\frac{64}{\operatorname{Re}_{\text {vent }}} & \operatorname{Re}_{\text {vent }}<2000 \\ {\left[1.14-2 \log \left(\frac{21.25}{\operatorname{Re}_{\text {vent }} 0.9}\right)\right]^{-2}} & \operatorname{Re}_{\text {vent }}>2000\end{cases}
$$

The minor losses due to the expansion from the vapor vents to the vapor core, estimated assuming flow through an abrupt expansion in cylindrical pipes, are negligible for the area ratios considered in this study.

The viscous vapor flow through the vapor core is assumed to incur a negligible pressure drop, due to the comparatively large cross-sectional area and expanding radius of the vapor core in the flow direction. The sum of liquid and vapor pressure drops gives the total pressure drop in the vapor chamber,

$$
\begin{aligned}
\Delta P_{\text {total }}= & \Delta P_{l, \text { bulk }}+\Delta P_{l, \text { cap }}+\Delta P_{l, \text { post }}+\Delta P_{l, \text { base }}+ \\
& \Delta P_{v, \text { space }}+\Delta P_{v, \text { vent }}+\Delta P_{v, \text { contraction }}
\end{aligned}
$$

For the chamber to operate at a given heat input, the total pressure drop should be less than the capillary pressure supported by the sintered wick, i.e., $\Delta P_{\text {total }} \Delta P_{c} \leq 1$ is a required condition for continued operation of the vapor chamber.

\section{B. Thermal resistances}

To calculate the temperature drop across the base wick due to capillary-fed boiling ( $\Delta T_{\text {boil }}$ ), the empirical correlation proposed by Smirnov [22] is used:

$$
C\left(\frac{\Delta T_{\text {boil }}-\Delta T^{*}}{d_{\text {pore }}}\right)^{5 / 6}=q\left(\frac{h_{f g} \sigma k_{l}^{3}}{v_{l}}\right)^{-1 / 6}\left(1-\phi_{e f f}\right)^{-1 / 6} k_{\text {eff }}^{-1 / 3}
$$

where

$$
\Delta T^{*}=\frac{4 \sigma T_{\text {sat }}}{\rho_{v} h_{f g} d_{\text {pore }}} ; k_{\text {eff }}=k_{C u} \frac{(1-\phi)}{(1+\phi / 2)} ; C=0.32
$$

This model assumes the capillary-fed boiling phenomenon can be represented by evaporation from a thin-liquid film coated over extended surfaces formed by the porous structure. The empirical constant $C$ is taken from a previous curve fit to a set of experimental capillary-fed boiling performance data [17]. In equation (21), $\Delta T^{*}$ is the nucleation superheat and $k_{e f f}$ is the effective thermal conductivity of the wick. The saturation temperature change in the vapor phase is calculated from the associated vapor pressure drops using the Clausius-Clapeyron relation

$$
\Delta T_{s a t}=\frac{T_{s a t} v_{f g}}{h_{f g}} \Delta P_{v}
$$

The temperature drops in the walls and the condenser wick are calculated assuming one-dimensional conduction as 
(a)

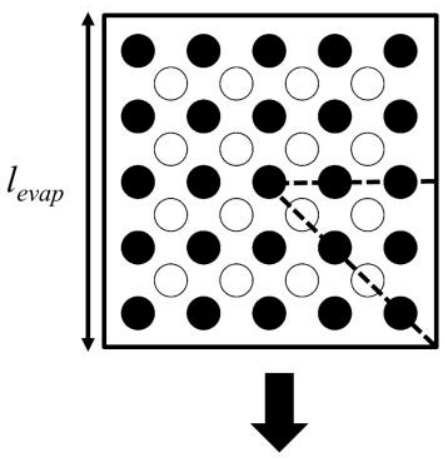

(b) One-eighth geometry

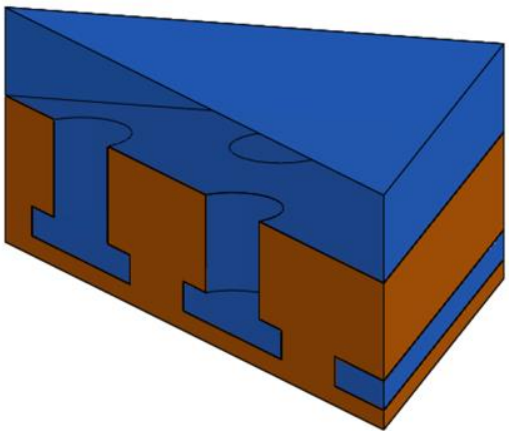

(c) Liquid domain (with mesh)

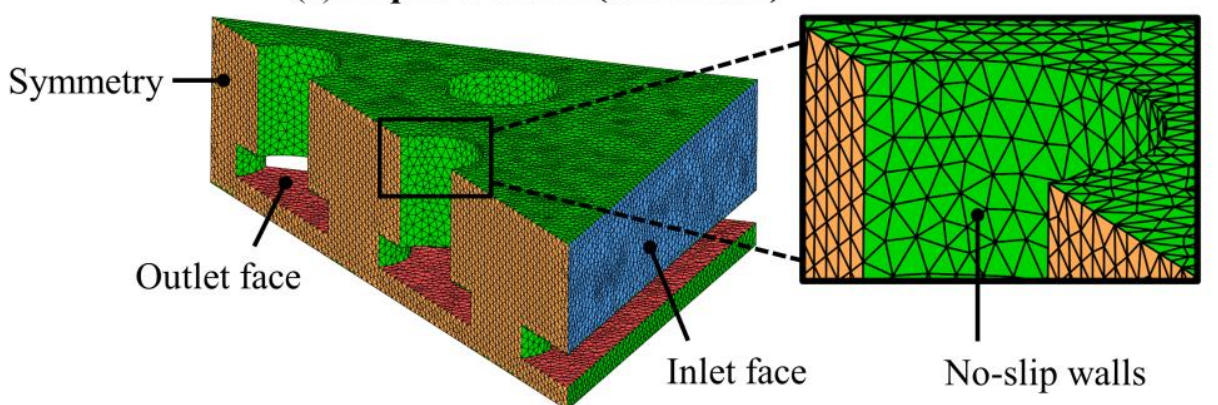

(d) Vapor domain (with mesh)
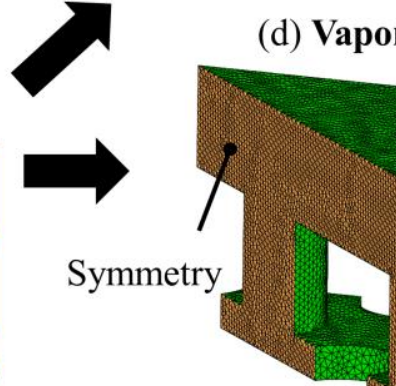

Inlet face (underneath)

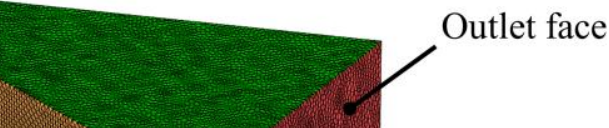

No-slip walls

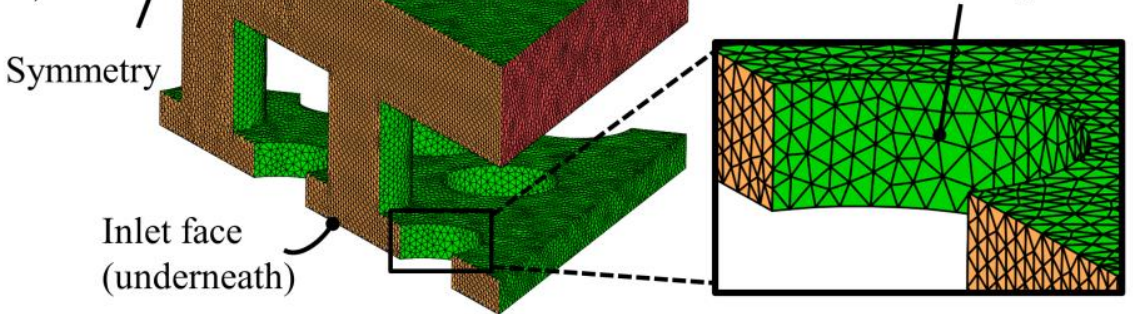

Fig. 3. (a) Plan view diagram of the evaporator footprint area of side length $l_{\text {evap }}$, for an example $5 \times 5$ array of posts with dashed lines showing one-eighth of the geometry. (b) Three-dimensional view of one-eighth section of the two-layer wick used for the numerical simulations, with the colors distinguishing the porous wick and vapor regions. The meshed (c) porous wick region (wick domain) and the (d) open region (vapor domain) are shown with the boundary conditions labelled, namely, the inlet, outlet, and symmetry, and no-slip boundaries. Insets in (c) and (d) show a close-up view of the mesh.

$$
\begin{aligned}
\Delta T_{\text {condn }} & =\Delta T_{\text {walls }}+\Delta T_{\text {wick, }, \text { cond }} \\
& =Q\left(\frac{t_{\text {wall }}}{A_{\text {evap }} k_{C u}}+\frac{t_{\text {wall }}}{A_{\text {cond }} k_{C u}}+\frac{t_{\text {wick, cond }}}{A_{\text {cond }} k_{\text {eff }}}\right)
\end{aligned}
$$

The total temperature drop is calculated by summing the individual temperature differentials:

$$
\Delta T_{\text {total }}=\Delta T_{\text {boil }}+\Delta T_{\text {sat }}+\Delta T_{\text {condn }}
$$

\section{VALIDATION OF REDUCED-ORDER MODEL}

The one-dimensional model description of the two-layer wick is validated by comparing to a numerical model that solves for the multi-dimensional fluid flow behavior. A fixed baseline two-layer wick geometry is used for this comparison. The porous wick is taken to be composed of cubic-packed $(\phi=0.48)$ sintered copper particles of mean diameter $d_{\text {part }}=100 \mu \mathrm{m}$. The working fluid considered is water. The thickness of the base wick layer $\left(t_{\text {base }}\right)$ is taken to be $200 \mu \mathrm{m}$. Fig. 3 (a) shows the plan view of the evaporator footprint area for the example case consisting of a uniform $5 \times 5$ array of posts and an offset $4 \times 4$ array of vents. The following additional dimensions of the twolayer wick and vapor core are chosen for the baseline: $d_{\text {post }}=1$ $\mathrm{mm}, d_{\text {vent }}=1 \mathrm{~mm}, t_{\text {base }}=0.2 \mathrm{~mm}, t_{\text {core }}=0.9 \mathrm{~mm}$.

\section{A. Numerical model for pressure drop in the two-layer wick}

In the numerical model, the two-layer wick structure is separated into a liquid flow domain consisting of the porous wick regions and a vapor flow domain consisting of the open spaces within the wick and in the vapor core. The threedimensional continuity and momentum equations are solved in one-eighth symmetric sections of these domains in ANSYS Fluent [24] to obtain the pressure drop values. A threedimensional view of the wick and vapor domains of the twolayer wick section is shown in Fig. 3 (b).

Fig. 3 (c) shows the meshed wick domain along with the boundary conditions imposed. The inlet to the domain is the outer face of the cap layer at the edge of the evaporator region. A pressure inlet boundary condition is specified on the inlet face with a constant (zero) value of gauge pressure. The domain outlet is the exposed top surface of the base wick layer where evaporation occurs. A mass outlet boundary condition is specified on the outlet face with a known evaporative mass flux based on the heat input, as calculated from the mass flow rate in equation (4). There are two symmetry boundaries, and the rest of the wick boundaries that interface with the vapor domain are modeled as no-slip walls. A porous-flow formulation of the governing equations that considers viscous and inertial dissipation accounting for the wick porosity $(\phi)$ and the permeability $(\mathrm{K})$ is used for the wick domain as seen in Ref. 
(a)

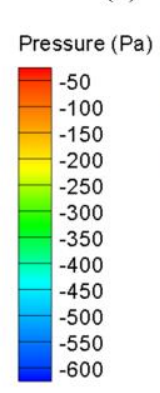

(b)

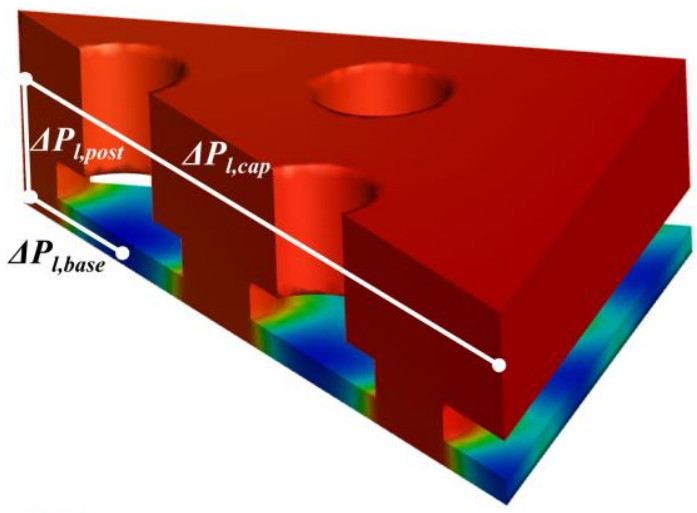

(c)

(d)
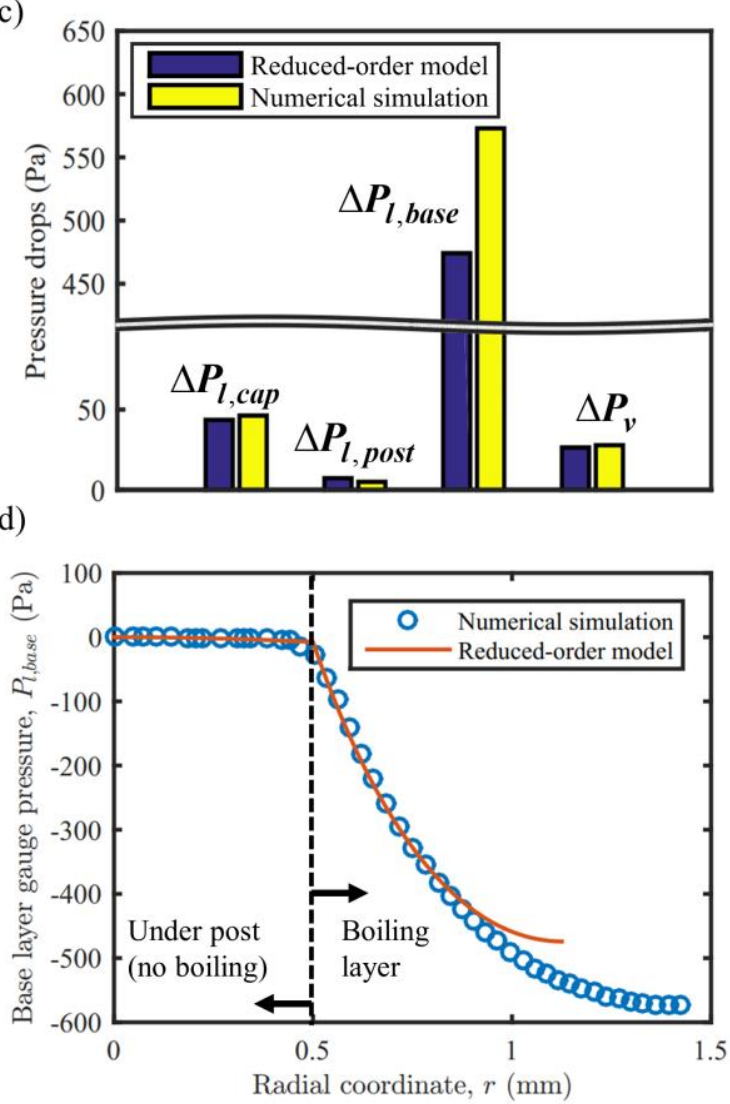

Fig. 4. Pressure contours predicted by the numerical simulation for the (a) wick and (b) vapor domains of the two-layer wick. Pressure drops are calculated along the cap layer $\left(\Delta P_{l, c a p}\right)$, post $\left(\Delta P_{l, p o s t}\right)$, and base layer $\left(\Delta P_{l, \text { base }}\right)$ as indicated by the lines in (a); the vapor flow pressure drop $\left(\Delta P_{v}\right)$ is calculated along the lines in (b). (c) A bar chart compares the pressure drop values calculated from the reduced-order model and the numerical simulation. (d) The gauge pressure is plotted radially along the base wick layer (i.e., along the line corresponding to the base layer pressure drop) for the reduced-order model and the numerical simulation.

[25]. Note that the evaporating portion of the base wick layer (i.e., not covered by liquid-feeding posts) is modeled with reduced values of porosity $\left(\phi_{e}\right)$ and permeability $\left(\mathrm{K}_{\mathrm{e}}\right)$ to simulate the capillary-boiling conditions, as in the reducedorder model (see section IV.A). Other inputs to the numerical solver include the thermophysical properties of the working fluid.

Fig. 3 (d) shows the vapor flow domain and the boundary conditions. The mass inlet boundary condition on the vapor domain is the top surface of the base wick layer, which mirrors the outlet face of the wick domain. Vapor flows through the space between liquid feeding posts, up the vapor vents, and expands into the large vapor core, ultimately flowing outward to the outlet face. A pressure outlet boundary condition is specified on the outlet face, with a constant (zero) value of gauge pressure. There are two symmetry faces while the remaining boundaries that interface with the wick domain are modeled as no-slip walls.

\section{B. Comparison of reduced-order and numerical models}

The two-layer wick geometry described in sub-section V.A is simulated for a heat input of $Q=100 \mathrm{~W}$. Fig. 4 (a) and (b) respectively show the liquid and vapor pressure contours predicted by the numerical model. A gradient-based mesh refinement was performed, wherein cells in regions of high pressure gradient were refined, to arrive at the results reported here, for meshes containing 160,000 cells in the wick domain and 425,000 cells in the vapor domain; further refinement in each case provided negligible change in the total pressure drop. In the wick domain (Fig. 4 (a)), the highest pressure gradient is along the thin base wick. Pressure contours in the base wick layer can be seen as rings around each post, indicating that the liquid flows radially around each post. In the vapor domain (Fig. 4 (b)), the pressure in the vapor core remains largely uniform, except for localized higher pressure regions above each vent. The highest pressure regions are near the outer edge of the evaporator region within the vapor spaces between the liquid-feeding posts; because there is no vent directly above these regions, vapor originating at the inlet face close to the edge must flow a relatively longer distance to reach the nearest vent, resulting in a larger pressure drop. The minimum pressure in the domain is at the start of each vent, because the flow encounters a sudden contraction and turns into the narrow vapor vents from the wider vapor space between the posts.

The pressure drops across different regions in the wick and vapor domain predicted by the numerical simulation are compared with corresponding values from the reduced-order model predictions. As shown in Fig. 4 (a), the pressure drop in 
(a)

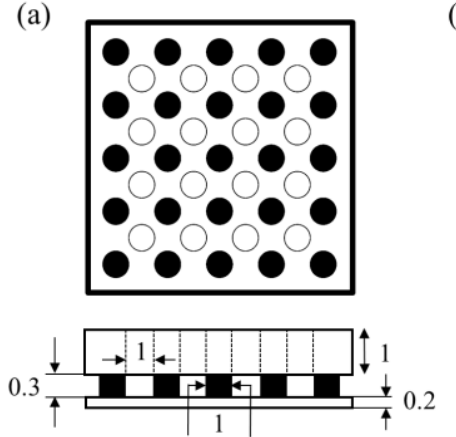

(b)

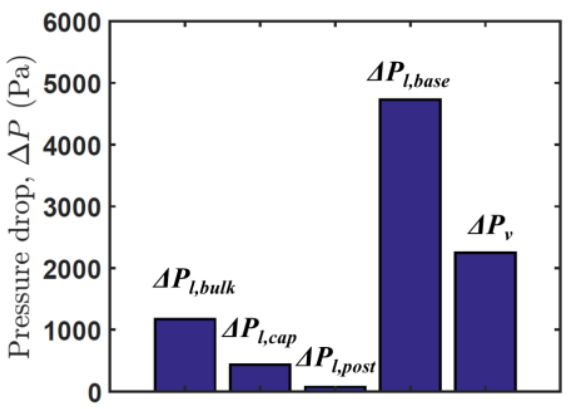

(c)

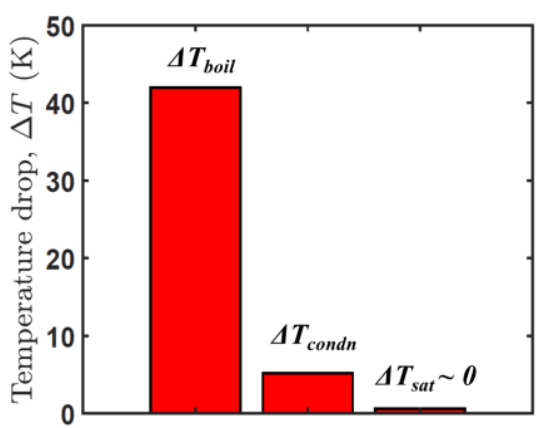

Fig. 5. (a) Plan and side-view drawings of an example two-layer evaporator wick design case; in the plan view, liquid-feeding posts are filled circles and vents are open dots (dimensions shown in mm, not to scale). Histograms are shown for the different (b) pressure drops and (c) temperature drops for this baseline case at a heat input of $Q=1 \mathrm{~kW}$ over $1 \mathrm{~cm}^{2}$ of heat input area.

the cap layer of the wick domain $\left(\Delta P_{l, c a p}\right)$ is calculated across a line along the middle of the cap layer from the inlet to the center of the domain. The pressure drop along the post $\left(\Delta P_{l, p o s t}\right)$ is calculated along the centerline of the centermost post in the array; the pressure drop and the mass flow rate are nearly the same across all the posts. The base layer pressure drop $\left(\Delta P_{l, \text { base }}\right)$ is calculated along a line from the middle post outward to the point of minimum pressure in the domain, diagonally between the posts. In the vapor domain, the total vapor pressure drop $\left(\Delta P_{v}\right)$ is calculated along the centerline of a vent starting from the inlet face, and then along the vapor core leading to the outlet face. However, the pressure drop differs for each vent because the pressure over the inlet face is non-uniform; an average value of pressure drop is calculated by averaging the total vapor pressure drop calculated along the centerlines of the three vents. This average value of vapor pressure drop is used in the comparison to the reduced-order model prediction.

Fig. 4 (c) shows a bar chart of the different pressure drops in the numerical simulation compared to the corresponding values from the reduced-order model. It is noted that the largest difference is in the base wick layer (17\%), while the other pressure drop values match within 5\%. The difference observed in the base wick layer pressure drop is explained with Fig. 4 (d), which shows the gauge pressure along the base layer in the numerical simulation compared to the radial flow approximation from the reduced-order model. Pressure remains almost constant under the post (where boiling does not occur), and drops rapidly outside the post due to the reduced porosity and permeability in the boiling wick. While the pressure gradient matches between the simulation approaches, the flow length in the base wick layer is shorter in the reduced-order model due to the simplified one-dimensional assumption that calculates the flow length based on the area of the unit cell given by equation (11). In the numerical simulation, the flow length is slightly larger and there is a minimum pressure region in the base layer diagonally between the posts. Overall, it is concluded that the reduced-order model adequately represents the nature of the fluid flow in the two-layer wick and provides a satisfactory prediction of the total pressure drop.

\section{TWO-LAYER WICK PERFORMANCE PREDICTION}

The reduced-order model developed in Section IV can be used to find two-layer evaporator wick designs that are capable of sustaining liquid supply at a given heat input while maintaining a target evaporator temperature. Various vapor chamber dimensions are held constant for the analysis. The thicknesses of the vapor chamber walls $\left(t_{\text {wall }}\right)$ and the condenser-side wick $\left(t_{\text {wick,cond }}\right)$ are each set to $200 \mu \mathrm{m}$. The condenser and the evaporator square edge lengths are $l_{\text {cond }}=100$ $\mathrm{mm}$ and $l_{\text {evap }}=10 \mathrm{~mm}$, respectively. The bulk wick thickness $t_{\text {bulk }}$ is chosen to be $1.5 \mathrm{~mm}$ with a total vapor chamber thickness of $3 \mathrm{~mm}$.

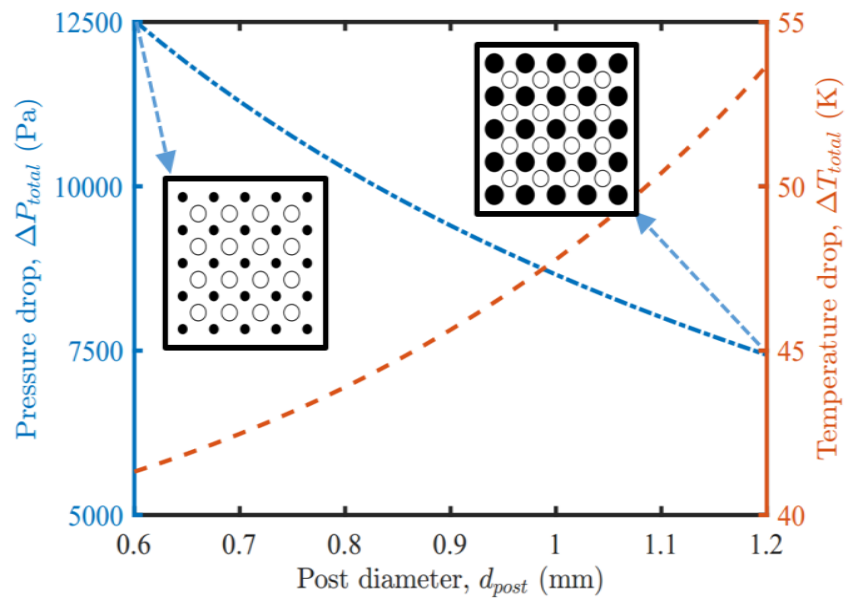

Fig. 6. Effect of post diameter on the total pressure drop and the total temperature drop, for $d_{v e n t}=1 \mathrm{~mm}$ and $t_{c a p}=1 \mathrm{~mm}$, with all other wick geometric parameters fixed as in the baseline case. The insets show plan-view drawings (to scale) of the two-layer evaporator wick designs at the extreme post diameters. 


\section{A. Relative magnitude of pressure drops and temperature drops}

A baseline two-layer evaporator wick design is analyzed first in order to assess the relative magnitude of the different pressure and temperature drops at a heat input of $Q=1 \mathrm{~kW}$ (i.e., flux of $1 \mathrm{~kW} / \mathrm{cm}^{2}$ ). The baseline case is the same as specified in Section V. Fig. 5 (a) shows drawings of the baseline design, which has a uniform $5 \times 5$ square array of liquid feeding posts and an offset $4 \times 4$ square array of vapor vents, with the following geometrical parameters: $d_{\text {post }}=1 \mathrm{~mm}, d_{\text {vent }}=1 \mathrm{~mm}$, and $t_{\text {cap }}=1 \mathrm{~mm}$.

Fig. 5 (b) provides a histogram of the different liquid pressure drops and the total vapor pressure drop. The maximum pressure drop is incurred in the thin base wick $\left(\Delta P_{l, \text { base }}\right)$; this large pressure drop is due to the small cross section for flow that is further reduced by vapor formation, even over the short flow length. The bulk wick and cap wick layer liquid pressure drops are higher than that in the liquid feeding posts, as a result of this specific design case having relatively thick posts; generally, these pressure drops are of a similar magnitude, depending on the design. The vapor pressure drop also contributes a significant portion to the total pressure drop for this particular design, but can be significantly reduced for wider vents. To a large extent, $\Delta P_{l, \text { base }}$ governs the overall pressure drop in the vapor chamber. A sufficiently dense array of liquid-feeding posts (i.e., more unit cells with a decreased flow length in the base wick layer) would be necessary to reduce this pressure drop such that a capillary limit is not encountered. This highlights the need for distributed liquid feeding with an array of posts to enable use of the thin base wick over the entire $1 \mathrm{~cm}^{2}$ evaporator area.

A histogram of the different temperature drops for the example design is shown in Fig. 5 (c). The boiling resistance induces the highest temperature drop and represents the limiting factor on the thermal performance of a vapor chamber incorporating the two-layer wick design. This temperature drop is amplified by the reduction in footprint area for capillary-fed boiling due to the presence of posts (from which boiling is assumed not to occur). Therefore, the thermal performance of the vapor chamber is expected to be sensitive to the diameter of the liquid-feeding posts, which determine the amplification of the heat flux. While the conduction temperature drops are not negligible, they are a part of the vapor chamber design and not of the two-layer wick proposed in this work, and hence not a primary focus here. The saturation temperature change in the vapor phase is negligible. Considering that the base layer pressure and temperature drops largely govern the performance, note that the model predictions are reliant on the accuracy of the correlations used to predict these terms; given the sensitivity of the performance predictions to the base wick thickness, the value in this study was chosen to match the thickness and particulate composition of a wick investigated in prior experiments from which the capillary-fed boiling empirical correlation parameters adopted in this study were developed [26]. In addition, keeping this wick thickness small is central to the design concept and helps achieve the low evaporator temperatures desired.

\section{B. Parametric effects on performance}

The effects of the two-layer wick post diameter, cap layer thickness, and the vent diameter on the pressure drop and thermal performance are investigated for a $5 \times 5$ post array design. As any one of these parameters is varied individually, the other two parameters remain fixed at the baseline values of $d_{\text {post }}=1 \mathrm{~mm}, d_{\text {vent }}=0.5 \mathrm{~mm}$, and $t_{\text {cap }}=1 \mathrm{~mm}$; all other wick geometric parameters are the same as the baseline case and the heat input remains $Q=1 \mathrm{~kW}$.

Fig. 6 shows the total pressure drop, $\Delta P_{\text {total }}$ (left vertical axis; blue line) and the total temperature drop, $\Delta T_{\text {total }}$ (right vertical axis; red line) plotted against the post diameter, keeping all

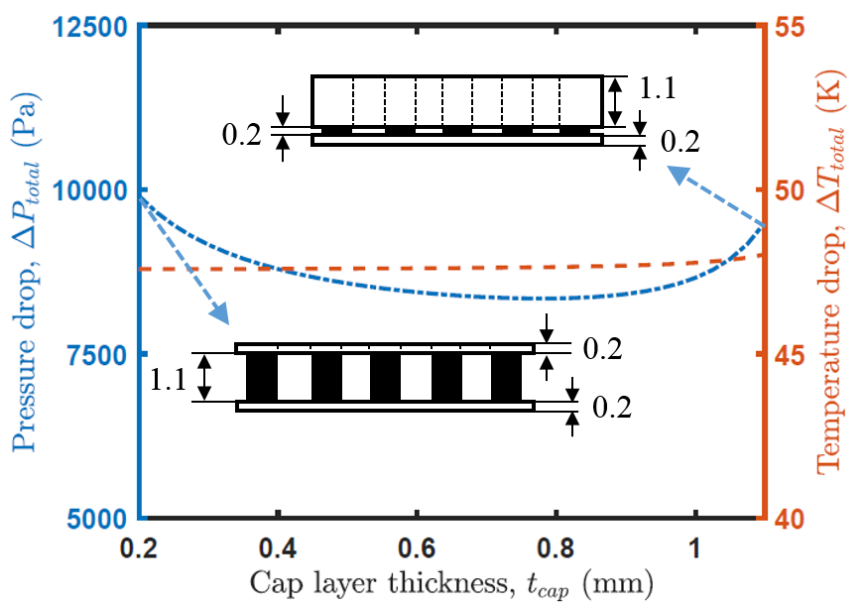

Fig. 7. Effect of cap layer thickness on the total pressure drop and the total temperature drop, for $d_{\text {post }}=1 \mathrm{~mm}$ and $d_{\text {vent }}=$ $1 \mathrm{~mm}$, with all other wick geometric parameters fixed as in the baseline case. Insets show side-view drawings of the two-layer wick at the extreme cap layer thicknesses (not to scale, dimensions in $\mathrm{mm}$ ).

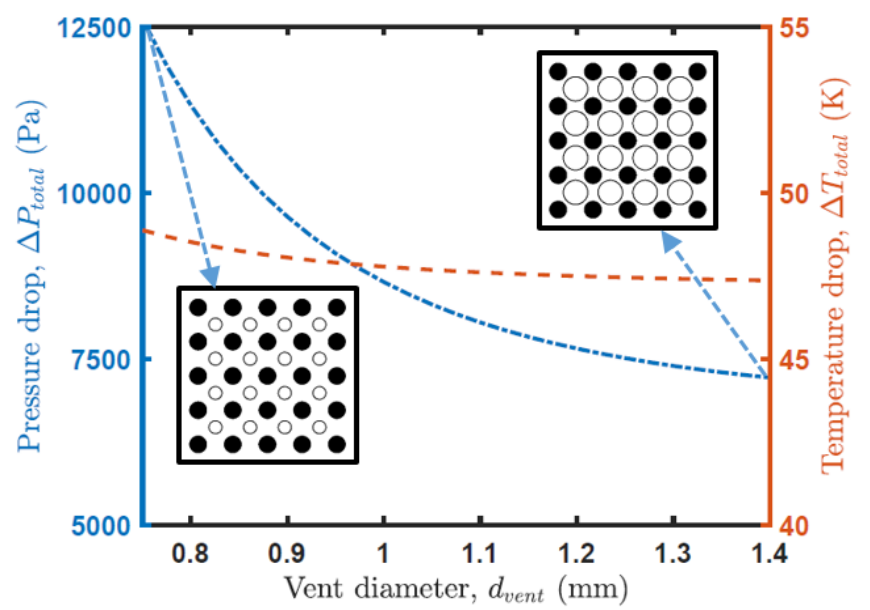

Fig. 8. Effect of vent diameter on the total pressure drop ratio and the total temperature drop, for $d_{\text {post }}=1 \mathrm{~mm}$ and $t_{\text {cap }}=1$ $\mathrm{mm}$, with all other wick geometric parameters fixed as in the baseline case. Insets show scaled evaporator areas for extreme cases of vent diameters. 
other wick geometric parameters fixed. For a fixed array size, increasing the post diameter reduces the total pressure drop. Thicker posts reduce the pressure drop contribution from the posts; more importantly, the flow length in the thin base wick layer is shortened, thereby decreasing the total pressure drop. Conversely, the temperature difference across the vapor chamber increases with post diameter; thicker posts occupy a large area of the evaporator footprint, reducing the area available for boiling.

Fig. 7 plots $\Delta P_{\text {total }}$ and $\Delta T_{\text {total }}$ against the cap layer thickness, while keeping other wick geometric parameters fixed. Note that for constant bulk wick and base wick layer thicknesses, a change in the cap layer thickness implies a concomitant elongation or shortening of the liquid feeding posts. Therefore, when the cap layer thickness is reduced, the liquid pressure in the thinner cap $\left(\Delta P_{l, \text { cap }}\right)$ and longer posts $\left(\Delta P_{l, p o s t}\right)$ both increase. Conversely, increasing cap layer thickness yields shorter posts with narrower spaces between them, which increases the vapor pressure drop $\left(\Delta P_{v, \text { space }}\right.$ and $\left.\Delta P_{v, \text { vent }}\right)$. This tradeoff gives rise to an optimum cap thickness at which the total pressure drop is minimized ( $\sim 0.8 \mathrm{~mm}$ in Fig. 7), for all other parameters fixed. The temperature drops remain almost constant with cap thickness, with the only effect being a small increase in the saturation temperature change in the vapor phase at larger cap thicknesses for which vapor flow is restricted in the narrow spaces between posts.

The effect of vent diameter on $\Delta P_{\text {total }}$ and $\Delta T_{\text {total }}$ is shown in Fig. 8. In general, wider vapor vents increase the pressure drop through the cap layer $\left(\Delta P_{l, \text { cap }}\right)$ because the effective liquid flow area is reduced, while narrower vents increase the vapor pressure drop through the vent itself $\left(\Delta P_{v, v e n t}\right)$. Despite this apparent tradeoff, the pressure drop increase due to narrowed vents outweighs any decrease in the cap layer pressure drop. This analysis indicates that the vent diameters should be made as large as possible, up to the physical limit of overlapping with the liquid-feeding posts, to minimize the total pressure drop for a given array size. The thermal performance is largely unchanged within the range of vent diameters tested, as a result of the negligible contribution of the vapor vents to the saturation pressure change.

A comparative interrogation of Fig. 6 to Fig. 8 reveals that the pressure drop and the thermal resistance of the two-layer wick structure are predominantly affected by the post and vent diameters at a given array size; the cap layer thickness has a significantly smaller effect. This is because the post diameter directly influences the largest contributing pressure drop $\left(\Delta P_{l, \text { base }}\right)$ and temperature drop $\left(\Delta T_{\text {boil }}\right)$, and the vent diameter affects the non-negligible vapor pressure drop $\left(\Delta P_{v}\right)$. In addition, note that the total pressure drop for the baseline case, and parametric variations thereof, were always greater than the available capillary pressure of the wick structure $\left(P_{c}=5891\right.$ $\mathrm{Pa})$.

The number of liquid feeding posts in the array can be varied to design a two-layer evaporator wick structure with reduced pressure drop. Plotted in Fig. 9 are the pressure drop ratio $\left(\Delta P_{\text {total }} / \Delta P_{c}\right)$, left vertical axis; blue line) and the total temperature drop ( $\Delta T_{\text {total }}$, right vertical axis; red line) with varying array sizes, from a sparse $5 \times 5$ array to a densely packed $10 \times 10$ array of posts. A pressure drop ratio $\left(\Delta P_{\text {total }} / \Delta P_{c}\right)$ value of less than unity (a solid blue cut-off line at unity is shown in the figure) signifies that the vapor chamber can operate without reaching a capillary limit at the given heat flux. To design for a nearly fixed total temperature differential, the post diameter can be reduced as the array size increases, to

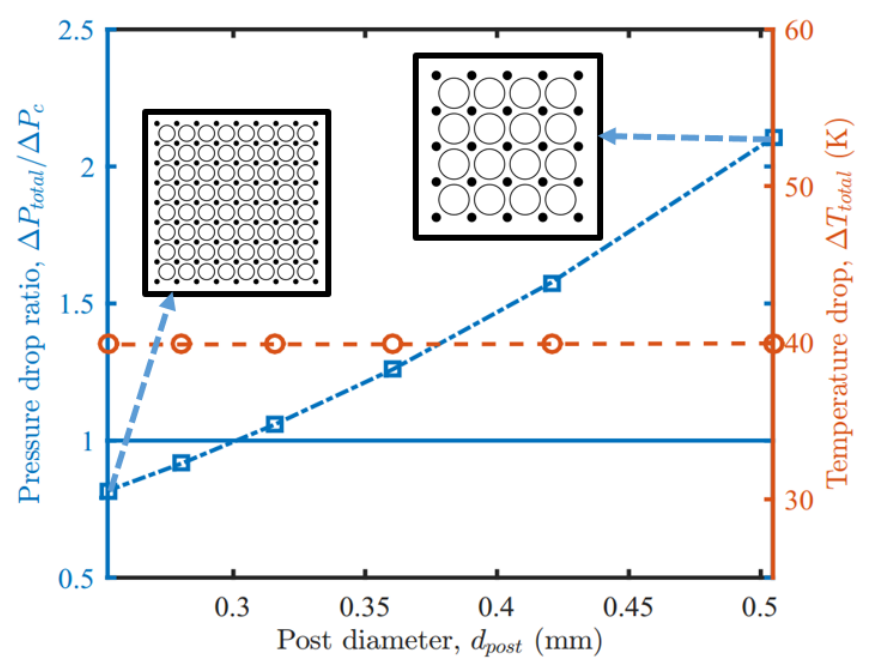

Fig. 9. Effect of increasing post array size on the total pressure drop ratio $\left(\Delta P_{\text {total }} \Delta P_{c}\right)$ and the total temperature drop $\left(\Delta T_{\text {total }}\right)$ for $d_{v e n t}=1 \mathrm{~mm}, t_{c a p}=1 \mathrm{~mm}$. This is achieved by fixing the footprint area covered by the posts to obtain a target temperature drop, while varying post diameter $\left(d_{p o s t}\right)$. Insets show scaled evaporator areas for a $5 \times 5$ and a $10 \times 10$ array of posts.

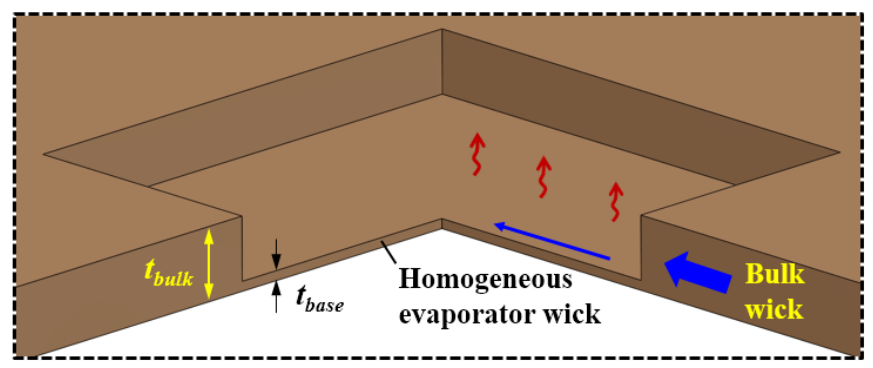

(a)

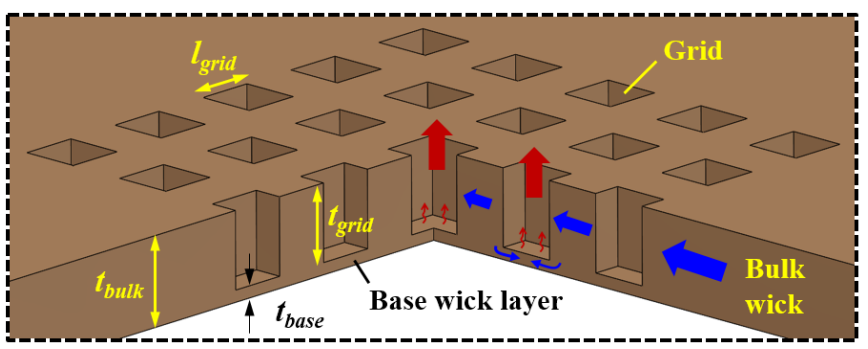

(b)

Fig. 10. Schematic drawings of (a) homogeneous and (b) gridpatterned evaporator wicks. Important characteristic dimensions of the two wicks, along with the primary liquid flow pathway (in blue arrows) and vapor flow pathway (in red arrows), are shown. 
maintain the associated footprint area covered by the posts. In Fig. 9, the footprint area is chosen such that the total temperature drop is $\sim 40 \mathrm{~K}$ across the different array sizes; the corresponding post diameter is shown on the abscissa. It is noted that increasing array sizes yield reduced total pressure drop due to the reduced flow length around each post in the base layer, thereby reducing the predominant $\Delta P_{l, b a s e}$. Arrays of size $9 \times 9$ and larger yield a pressure drop below the critical limit in this case.

As demonstrated in this section, the reduced-order model developed in this study allows for study of the design trade-offs resulting from changes to the two-layer wick geometry. These trade-offs must be considered so that an evaporator design avoids the capillary limit while achieving some target vapor chamber thermal resistance at a given heat input. The model can be exploited to generate two-layer wick designs for various device heat input and thermal resistance needs.

\section{PERFORMANCE ADVANTAGES OF PROPOSED TWO-LAYER WICK OVER SINGLE-LAYER WICKS}

The reduced-order model developed in this work helped estimate the performance of the two-layer wick design. In this section, similar reduced-order models for conventional singlelayer wick designs are used to assess the relative performance advantages of the two-layer wick. Specifically, homogeneous and grid-patterned evaporator wick designs (schematic diagrams in Fig. 10) are compared to the two-layer wick. The homogeneous wick has a uniform-thickness $\left(t_{\text {base }}\right)$ wick layer over the evaporator region to which liquid is supplied by a thick bulk wick $\left(t_{\text {bulk }}\right)$ around the periphery. The grid-patterned evaporator wick structure has square grids (length $l_{\text {grid }}$ ) running across the evaporator region to enhance liquid feeding of the thin wick base layer (thickness $t_{\text {base }}$ ) during high-heat-flux capillary-fed boiling operation $[9,11,26]$. In order to maintain a constant thermal resistance for each of the different evaporator wicks while assessing the pressure drop imposed, the same value of $t_{\text {base }}=200 \mu \mathrm{m}$ is used for all the wicks. All the wick and working fluid properties, including the particle, pore diameter and porosity of the wick, are kept the same as in the two-layer wick model (Sections IV and V). The dimensions of the vapor chamber, including the evaporator area of $1 \mathrm{~cm}^{2}$ used in Section VI, also remain the same. The reduced-order models developed for the homogeneous and grid-patterned evaporator wick designs are summarized in the Appendix. The remainder of this section compares their performance against the twolayer wick design proposed in this work.

The total pressure drop and thermal resistance of the homogeneous and grid-patterned evaporator wicks are calculated at a heat input of $Q=1 \mathrm{~kW}$. For the homogeneous evaporator wick, the total pressure drop is very high due to the small cross-sectional area available for liquid flow in the thin base layer without any additional feeding pathways. The pressure drop ratio (ratio of total fluid pressure drop to the capillary pressure) for the homogeneous evaporator wick is $\sim 17$ at a heat input of $Q=1 \mathrm{~kW}$. This ratio is very high compared to any of the two-layer wick designs assessed in Section VI and indicates that the homogeneous evaporator wick would dry out at a very low heat flux.

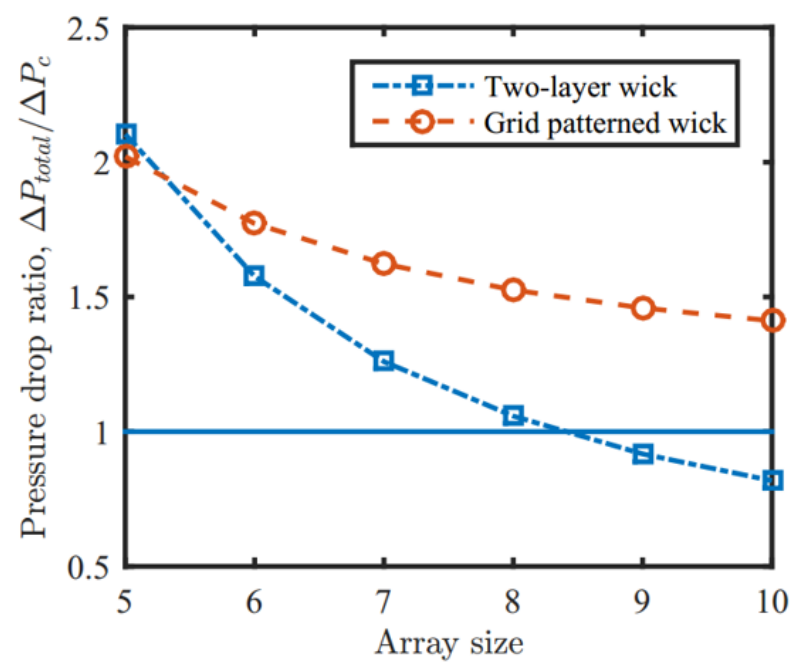

Fig. 11. Comparison of the pressure drop performance of the two-layer wick and the grid-patterned wick for varying array sizes. The blue line at a pressure drop ratio of 1 signifies the cut-off for operation of the vapor chamber due to the capillary limit.

Table I

Pressure drop ratios and temperature drops for the three different evaporator wicks, at a heat input of $Q=1 \mathrm{~kW}$ over an area of $1 \mathrm{~cm}^{2}$

\begin{tabular}{|c|c|c|}
\hline Wick structure & $\begin{array}{c}\text { Feature } \\
\text { array size }\end{array}$ & $\begin{array}{c}\text { Pressure drop ratio } \\
\left(\Delta P_{\text {total }} / \Delta P_{c}\right) \\
\end{array}$ \\
\hline $\begin{array}{c}\text { Homogeneous } \\
\text { wick }\end{array}$ & & 17 \\
\hline \multirow{3}{*}{$\begin{array}{l}\text { Grid-patterned } \\
\text { wick }\end{array}$} & $6 \times 6$ & 1.8 \\
\hline & $8 \times 8$ & 1.5 \\
\hline & $10 \times 10$ & 1.4 \\
\hline \multirow[t]{3}{*}{ Two-layer wick } & $6 \times 6$ & 1.7 \\
\hline & $8 \times 8$ & 1.1 \\
\hline & $10 \times 10$ & 0.8 \\
\hline
\end{tabular}

The pressure drop ratio of the grid-patterned evaporator wick is compared to the two-layer wick in Fig. 11. The results are obtained at a constant temperature drop of $\sim 40 \mathrm{~K}$ over all the cases, to compare the pressure drop performance of the wicks. The array size for the grid-patterned wick refers to the number of grids, while the array size for the two-layer wick refers to the number of posts in each direction of the square array. The twolayer wick outperforms (i.e., has a lower pressure drop ratio than) the grid-patterned wick as the array size increases. It is noted that for the grid-patterned wick, increasing array size does not produce a sufficient reduction in the pressure drop ratio, and thus a viable geometry for operation of the vapor chamber without a capillary limit is not reached. In contrast, the two-layer wick exhibits a significant reduction in the pressure drop ratio with increasing array size. This behavior can be explained by the design constraints that apply to each wick type. The same amount of evaporator footprint must be made available for capillary-fed boiling to keep the temperature drop at $\sim 40 \mathrm{~K}$, irrespective of the array size. For the grid-patterned 
wick, this necessitates a decrease in the width of the liquidfeeding pathways, and hence an increase in the pressure drop. For the two-layer wick, increasing the array sizes requires a larger number of thinner posts, which does not incur a large pressure drop penalty because they are all drawing from the same, thick cap layer. A summary of the comparison of the performance of the different evaporator wicks is tabulated in Table I. The reduced pressure drop offered by the two-layer wick design, at the same thermal resistance, indicates that this design offers the potential to dissipate higher heat fluxes than the other two wick structures before the capillary limit would be reached.

\section{CONCLUSIONS}

A two-layer vapor chamber evaporator wick structure is evaluated. To support high-heat-flux operation during capillary-fed boiling, evaporator wicks must be adequately fed with working fluid over their entire area while imposing a low thermal resistance. The two-layer evaporator design has a thin base wick layer supplied by an array of liquid-feeding posts from a thicker cap wick layer above. Vapor formed by boiling in the wick base layer passes out of the evaporator through the spaces between the posts and vapor vents in the cap layer. The base wick imposes a low thermal resistance during capillaryfed boiling, while the cap layer and liquid-feeding posts are responsible for providing uniform liquid supply over the entire evaporator area.

A reduced-order model is developed to predict the hydraulic and the thermal performance of the two-layer wick incorporated within a vapor chamber heat spreader. Comparing against a higher-fidelity numerical model, it is found that the reducedorder, one-dimensional model adequately represents the fluid flow behavior and the pressure drop in the two-layer wick. Parametric studies identified that the number and size of liquidfeeding posts critically affects both the pressure drop and thermal performance. Large arrays with smaller diameter posts can reduce the total pressure drop while maintaining the same area available for capillary-fed boiling in the base wick (i.e., maintaining constant thermal resistance). The reduced-order model predicts that heat fluxes on the order of $\sim 1 \mathrm{~kW} / \mathrm{cm}^{2}$ can be dissipated over areas as large as $1 \mathrm{~cm}^{2}$ without suffering from dryout by utilizing a sufficiently large number of liquid-feeding posts. The reduced-order model uses first-order approximations to provide useful insights into the design of the proposed twolayer evaporator wick structure. Comparison to other singlelayer wick structures (homogeneous and grid-patterned wicks) shows that the two-layer wick has a lower pressure drop at the target heat fluxes, such that the capillary limit (dryout) would not be reached.

\section{APPENDIX A REDUCED ORDER MODEL OF HOMOGENEOUS AND GRID-PATTERNED EVAPORATOR WICK STRUCTURES}

Fig. A. 1 (a) and (b) show the pressure and temperature drops along the primary fluid flow path in the homogeneous and gridpatterned wick structures. Similar to the two-layer wick reduced-order model (Section IV), a representative radial flow domain is considered in each case for the calculation of the pressure drop. The effective radius of the evaporator $\left(r_{\text {evap }}\right)$ is calculated based on the footprint area given by the square edge length $\left(l_{\text {evap }}\right)$. The liquid returning from the periphery of the vapor chamber incurs the same bulk liquid pressure drop, $\Delta P_{l, b u l k}$, as was given for the two-layer wick in equation (6).

For the homogeneous wick, the liquid pressure drop through the evaporator wick of thickness $t_{\text {base }}\left(\Delta P_{l, h}\right)$ is calculated by integrating the governing momentum equation from the limit of $r=r_{\text {evap }}$ to $r=0$, using the reduced porosity $\left(\phi_{\text {eff }}\right)$ and permeability $\left(K_{\text {eff }}\right)$ for the liquid flow through the base wick layer. This yields:

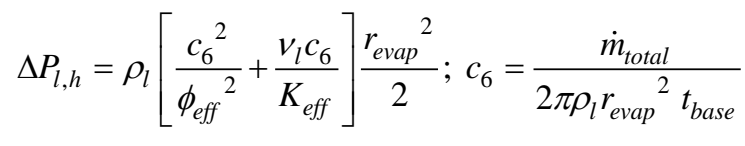

The vapor pressure drop is assumed to be negligible because of the wide area available for vapor flow out of the homogeneous evaporator wick and through the vapor core. The total pressure drop for the homogeneous wick is the sum of the bulk wick and the base wick layer pressure drops, i.e., $\Delta P_{\text {total }, h}=\Delta P_{l, \text { bulk }}+\Delta P_{l, h}$.

For the grid-patterned evaporator wick, liquid from the bulk wick flows through the grid-patterned area to the center of the evaporator. The evaporator region can be split into a 'grid layer', which is the thickness of the wick that contains the square liquid feeding structures (the grids), and a 'base' layer wick underneath the grids. Liquid pressure drop through the grid layer is calculated assuming a uniform extraction of liquid to the base layer below. The mass flow rate of liquid is a function of radial position and decreases from $\dot{m}_{\text {total }}$ at the evaporator periphery $\left(r_{\text {evap }}\right)$ to zero at the center:

$$
\dot{m}_{l, \text { grid }}(r)=\dot{m}_{\text {total }}\left(r^{2} / r_{\text {evap }}^{2}\right)
$$

A grid layer liquid flow velocity is calculated as

$$
u_{l, \text { grid }}(r)=\dot{m}_{l, \text { grid }} /\left(\rho_{l} 2 \pi r t_{\text {grid }, \text { eff }}\right)
$$

where, to account for the reduced area available for flow due to the openings in the grid, a reduced effective thickness of the layer $t_{\text {grid,eff }}$ is calculated based on the equivalent volume. Integrating equation (3) from $r=r_{\text {evap }}$ to $r=0$, the grid layer pressure drop is,

$$
\Delta P_{l, \text { grid }}=\rho_{l}\left[\frac{c_{7}^{2}}{\phi^{2}}+\frac{v_{l} c_{7}}{K}\right] \frac{r_{\text {evap }}^{2}}{2} ; c_{7}=\frac{\dot{m}_{\text {total }}}{2 \pi \rho_{l} r_{\text {evap }}^{2} t_{\text {grid }, \text { eff }}}
$$

In the base layer, liquid is assumed to flow inward in a unit cell around each grid. This unit cell spans a circular area of radius $r_{\text {eff, grid }}$ around each grid (radius $r_{\text {grid }}$ ), as shown in Fig. A. 2. The total mass flow rate is equally divided among the unit cells $\left(\dot{m}_{l, \text { grid }}=\dot{m}_{\text {total }} / N_{\text {grid }}\right)$ and remains constant from $r=r_{\text {eff,grid }}$ to $r=r_{\text {grid }}$, while it reduces to zero at $r=0$ 


$$
\dot{m}_{l, \text { base }, \text { grid }}(r)= \begin{cases}\dot{m}_{l, \text { grid }} & r_{\text {grid }} \leq r \leq r_{\text {eff }, \text { grid }} \\ \dot{m}_{l, \text { grid }}\left[\frac{r^{2}}{r_{\text {grid }}^{2}}\right] & 0 \leq r \leq r_{\text {grid }}\end{cases}
$$

Integrating the governing momentum equation using the mass flow rate and velocity $u_{l, \text { base }}=\dot{m}_{l, \text { base, grid }}\left(2 \pi \rho_{l} r t_{\text {base }}\right)$, the pressure drop is

$$
\begin{aligned}
\Delta P_{l, \text { base }, \text { grid }} & =\frac{\rho_{l} c_{8}^{2}}{2 \phi^{2}}\left(\frac{1}{r_{\text {eff }, \text { grid }}^{2}}-\frac{1}{r_{\text {grid }}{ }^{2}}\right)+\frac{\mu_{l} c_{8}}{K} \ln \left(\frac{r_{\text {eff }, \text { grid }}}{r_{\text {grid }}}\right) \\
& +\frac{\rho_{l} r_{\text {grid }}{ }^{2}}{2}\left(\frac{c_{9}^{2}}{{\phi_{\text {eff }}}^{2}}+\frac{v_{l} c_{9}}{K_{\text {eff }}}\right)
\end{aligned}
$$

where,

$$
c_{8}=\frac{\dot{m}_{l, \text { grid }}}{2 \pi \rho_{l} t_{\text {base }}} ; c_{9}=\frac{\dot{m}_{l, \text { grid }}}{2 \pi \rho_{l} t_{\text {base }} r_{\text {grid }}{ }^{2}}
$$

The vapor pressure drop through the grids in the grid-patterned wick and through the vapor core is assumed to be negligible. Hence, the total fluid pressure drop of the grid-patterned wick is given by

$$
\Delta P_{\text {total }, \text { grid }}=\Delta P_{l, \text { bulk }}+\Delta P_{l, \text { grid }}+\Delta P_{l, \text { base }, \text { grid }}
$$

The thermal resistances for the vapor chamber with the homogeneous and the grid-patterned evaporator wick are calculated as done for the two-layer wick. The conduction resistances in the walls of the vapor chamber and the boiling resistance are given by equations (23) and (21) respectively. Note that in the calculation of the boiling resistance, a reduced evaporator area (area covered by the grids, where boiling occurs) is used for the grid-patterned wick while the complete evaporator area is used for the homogeneous wick. The thermal resistance due to the saturation temperature change is assumed to be negligible. The total thermal resistance in both cases is given by $\Delta T_{\text {total } h}=\Delta T_{\text {condn }}+\Delta T_{\text {boil }}$.
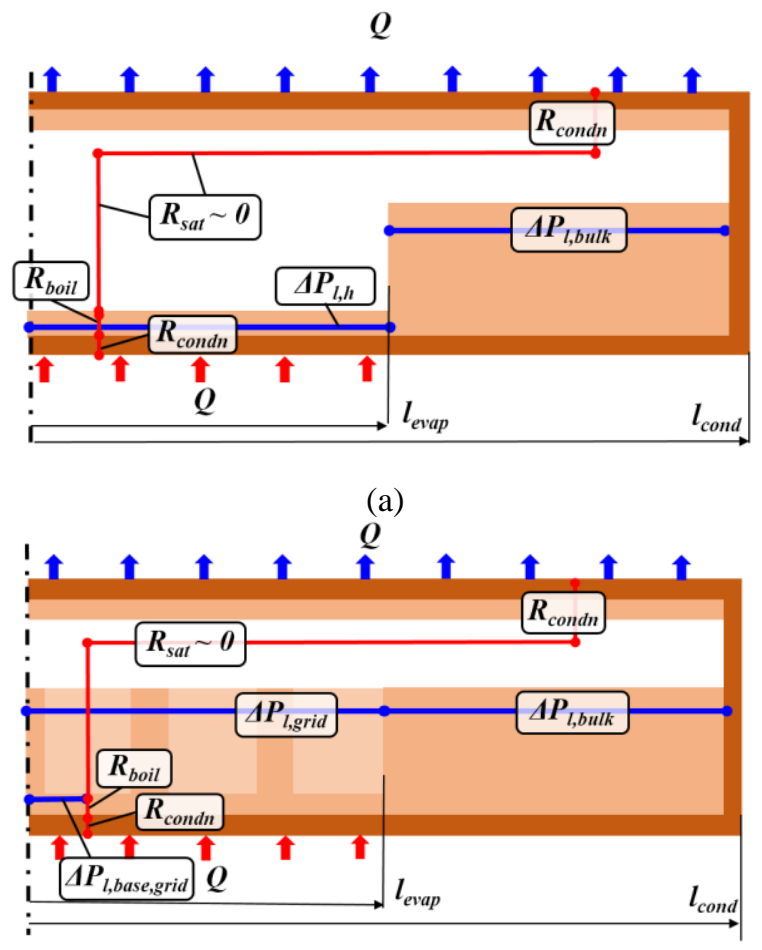

(b)

Fig. A. 1. Schematic drawings of cross-sections of a vapor chamber incorporating a (a) homogeneous and (b) gridpatterned wick. The pressure drops $(\Delta P)$ and thermal resistances $(R)$ along the primary fluid flow path are shown for both cases.

(a)

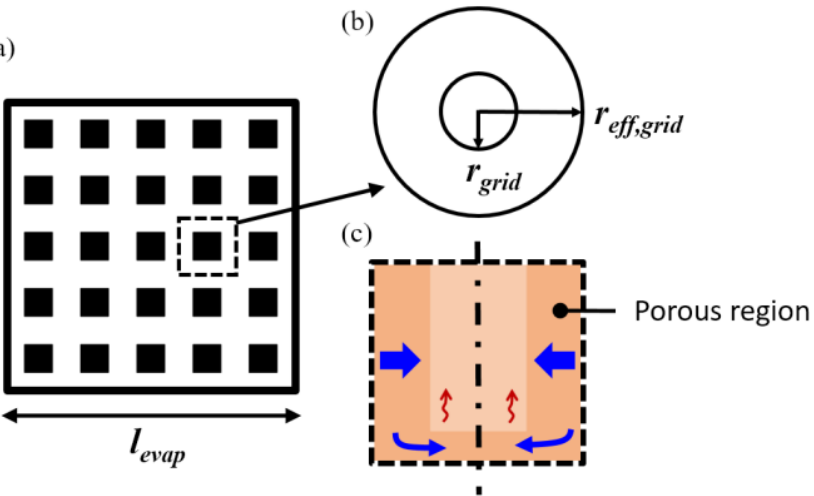

Fig. A. 2 (a) Plan view diagram of the grid patterned wick over the evaporator area for an example 5-by-5 grid pattern (filled squares). A square unit cell around a grid is outlined, which is approximated by an axisymmetric radial unit cell with (b) plan and (c) side views shown. 


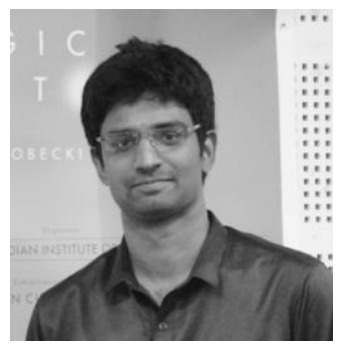

Srivathsan Sudhakar received his B.Tech degree in 2015, from the Indian Institute of Technology, Hyderabad, India. He is currently pursuing his Ph.D. degree in the School of Mechanical Engineering in Purdue University under the advisement of Dr. Suresh V. Garimella and Dr. Justin A. Weibel. Mr. Sudhakar's current research focuses on modeling and experimental characterization of phase change in porous wick structures for applications in vapor chamber passive heat spreaders, with emphasis on high-heat-flux dissipation.

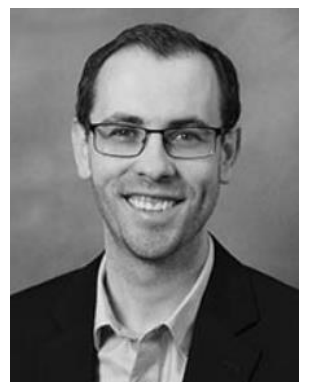

Justin A. Weibel is a Research Associate Professor in the School of Mechanical Engineering at Purdue University and serves as the Associate Director of the Cooling Technologies Research Center (CTRC). He received his $\mathrm{PhD}$ in 2012 and BSME in 2007, both from Purdue University. Dr. Weibel's research explores methodologies for prediction and control of phase-change and heat transport across interfaces to enhance the performance and efficiency of thermal management technologies, energy transfer processes, and other multiphase and psychrometric thermal systems. Projects span across fluid-thermal transport, surface and interfacial science, and microfabrication disciplines. He received the 2011 ASME Electronic \& Photonic Packaging Division (EPPD) Student Member of the Year Award.

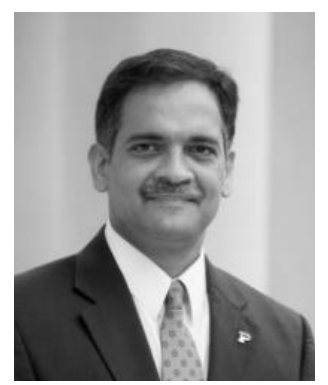

Suresh V. Garimella is the Executive Vice President for Research and Partnerships and the Goodson Distinguished Professor of Mechanical Engineering at Purdue University, West Lafayette, IN, USA, where he is also the Director of the National Science Foundation Cooling Technologies Research Center. He has supervised over $90 \mathrm{Ph} . \mathrm{D}$. and M.S. students, has co-authored 525 refereed journal and conference publications, and holds 13 patents. Twenty-four alumni from his research group are now faculty members at prestigious universities around the world. His research group has made seminal contributions to micro and nanoscale thermal and fluidic engineering, novel materials for thermal management, materials processing and manufacturing, and renewable energy. Dr. Garimella serves as editor with several leading journals. He is a Fellow of the National Academy of Inventors, and of AAAS and ASME. His contributions to thermal management were recognized with the 2016 ITHERM Achievement Award. 


\section{REFERENCES}

[1] Faghri, A., 1995, "Steady Hydrodynamic and Thermal Characteristics", in Heat Pipe Science and Technology, Washington, DC, USA: Taylor \& Francis, pp. 115-220.

[2] Williams, R. R., and Harris, D. K., 2006, "A device and technique to measure the heat transfer limit of a planar heat pipe wick," Experimental Thermal and Fluid Science, 30(3), pp. 277-284.

[3] Mughal, M. P., and Plumb, O. A., 1996, “An experimental study of boiling on a wicked surface," International Journal of Heat and Mass Transfer, 39(4), pp. 771-777.

[4] Brautsch, A., and Kew, P. A., 2002, "Examination and visualisation of heat transfer processes during evaporation in capillary porous structures," Applied Thermal Engineering, 22(7), pp. 815-824.

[5] Weibel, J. A., Garimella, S. V., and North, M. T., 2010, "Characterization of evaporation and boiling from sintered powder wicks fed by capillary action," International Journal of Heat and Mass Transfer, 53(19-20), pp. 42044215.

[6] Li, C., Peterson, G. P., and Wang, Y., 2006, "Evaporation/Boiling in thin capillary wicks (1) - Wick thickness effects," Journal of Heat Transfer, 128(12), pp. 1312-1319.

[7] Semenic, T., and Catton, I., 2009, "Experimental study of biporous wicks for high heat flux applications," International Journal of Heat and Mass Transfer, 52(2122), pp. 5113-5121.

[8] Weibel, J. A., Kousalya, A. S., Fisher, T. S., and Garimella, S. V., 2012, "Characterization and nanostructured enhancement of boiling incipience in capillary-fed, ultrathin sintered powder wicks," 2012 13th IEEE Intersociety Conference on Thermal and Thermomechanical Phenomena in Electronic Systems (ITherm), San Diego, CA, pp. 119-129.

[9] Ju, Y. S., Kaviany, M., Nam, Y., Sharratt, S., Hwang, G. S., Catton, I., Fleming, E., and Dussinger, P., 2013, "Planar vapor chamber with hybrid evaporator wicks for the thermal management of high-heat-flux and high-power optoelectronic devices," International Journal of Heat and Mass Transfer, 60, pp. 163-169.

[10] Weibel, J. A., Kim, S. S., Fisher, T. S., and Garimella, S. V., 2012, "Carbon nanotube coatings for enhanced capillary-fed boiling from porous microstructures," Nanoscale and Microscale Thermophysical Engineering, 16(1), pp. 1-17.

[11]Zhao, Y., and Chen, C.-L., 2006, "An investigation of evaporation heat transfer in sintered copper wicks with microgrooves," Proceedings of the ASME International Mechanical Engineering Congress and Exposition (IMECE), Chicago, IL, pp. 177-181.

[12] Bar-Cohen, Avram, 2013, "Gen-3 Thermal Management Technology: Role of Microchannels and Nanostructures in an Embedded Cooling Paradigm." Journal of
Nanotechnology in Engineering and Medicine 4(2), p. 20907.

[13] Cai, S. Q., and Bhunia, A., 2014, "Characterization of phase change heat and mass transfers in monoporous silicon wick structures," Journal of Heat Transfer, 136(7), p. 072001

[14] Cai, Q., and Chen, Y.-C., 2011, "Investigations of biporous wick structure dryout," Journal of Heat Transfer, 134(2), p. 021503

[15]Palko, J. W., Zhang, C., Wilbur, J. D., Dusseault, T. J., Asheghi, M., Goodson, K. E., and Santiago, J. G., 2015, "Approaching the limits of two-phase boiling heat transfer: High heat flux and low superheat," Applied Physics Letters, 107(25), p. 253903.

[16] Ćoso, D., Srinivasan, V., Lu, M.-C., Chang, J.-Y., and Majumdar, A., 2012, "Enhanced heat transfer in biporous wicks in the thin liquid film evaporation and boiling regimes," Journal of Heat Transfer, 134(10), p. 101501.

[17] Weibel, J. A., and Garimella, S. V., 2013, "Recent advances in vapor chamber transport characterization for high-heat-flux applications," Advances in Heat Transfer, 45, pp. 209-301.

[18] Weibel, J. A., Garimella, S. V., Murthy, J. Y., and Altman, D. H., 2011, "Design of integrated nanostructured wicks for high-performance vapor chambers," IEEE Transactions on Components, Packaging and Manufacturing Technology, 1(6), pp. 859-867.

[19] Hwang, G. S., Fleming, E., Carne, B., Sharratt, S., Nam, Y., Dussinger, P., Ju, Y. S., and Kaviany, M., 2011, "Multiartery heat-pipe spreader: Lateral liquid supply," International Journal of Heat and Mass Transfer, 54(1112), pp. 2334-2340.

[20] Min, D. H., Hwang, G. S., and Kaviany, M., 2009, "Multiartery, heat-pipe spreader," International Journal of Heat and Mass Transfer, 52(3-4), pp. 629-635.

[21] Prasher, Ravi S. "A Simplified Conduction Based Modeling Scheme for Design Sensitivity Study of Thermal Solution Utilizing Heat Pipe and Vapor Chamber Technology." Journal of Electronic Packaging 125, no. 3 (September 17, 2003): 378-85.

[22] Smirnov, 1977, "Approximate theory of heat transfer in porous structures." Thermal Engineering (Teploenergetika), 24, pp. 55-58.

[23] Blevins, R.D., 1984, "Applied fluid dynamics handbook" New York, Van Nostrand Reinhold Co.,568 p.

[24] ANSYS ${ }^{\circledR}$ FLUENT, Academic Research, Release 17.1

[25] "Porous media conditions", Section 7.2.3, ANSYS FLUENT 12.0 User's Guide. [Online]. Available: http://www.afs.enea.it/project/neptunius/docs/fluent/html/ ug/node233.htm

[26] Weibel, J. A., and Garimella, S. V., 2012, "Visualization of vapor formation regimes during capillary-fed boiling in sintered-powder heat pipe wicks," International Journal of Heat and Mass Transfer, 55(13-14), pp. 3498-3510. 